\title{
Who Gains from Information Asymmetry?
}

\author{
Gil S. Epstein ${ }^{1} *$ \\ Bar-Ilan University, CReAM, London and IZA, Bonn
}

and

Yosef Mealem

Netanya Academic College, Netanya, Israel

\begin{abstract}
This article considers an asymmetric contest with incomplete information. There are two types of players: informed and uninformed. Each player has a different ability to translate effort into performance in terms of the contest success function. While one player's type is known to both players, the other is private information and known only to the player himself. We compare the Bayesian Nash equilibrium outcome of a one-sided private information contest to the Nash equilibrium with no private information, in which both players know the type of the other player. We show conditions under which uncertainty increases the investment of the uninformed player and the rent dissipation of the contest, while decreasing the expected net payoff of the informed player. In addition, we consider conditions under which the informed player - before knowing his own type - prefers that the uninformed player knows his type. Moreover, we show conditions for the existence/non-existence of equilibrium in a two-stage contest in which the informed player declares his type (or does not declare) in the first stage and in the second stage the two players play according to the information available to them.
\end{abstract}

Keywords: Asymmetric contests, rent seeking, incomplete information.

JEL Classification: D72, C72

\footnotetext{
${ }^{1}$ Financial support from the Adar Foundation of the Economics Department of Bar-Ilan University is gratefully acknowledged.

* Corresponding author: Tel: 972-52-8550407, E-mail: Gil.Epstein@biu.ac.il
} 


\section{Introduction}

Asymmetry in the abilities of players in a contest can be found in many situations. Moreover, players do not always know the abilities of their opponents. For example, in a contest over monopoly regulation, where both the consumers and the producer invest effort in order to influence the decisions of politicians or regulators, it is not always clear how efficient the players are in using their resources. In this particular situation, the ability of consumers to influence politicians is usually known to both groups while the ability of the producer is usually unknown to the consumers. The asymmetry is a result of the fact that the consumers do not know how efficient the producer is in using its resources: do the politicians support or oppose granting monopoly power to the producer; does the producer have direct access to the politicians; do the politicians receive donations from the producer, etc. In this situation, the producer is the informed player since it knows both its own abilities and those of the consumers while the consumers know only their own abilities.

Another example involves an individual claiming compensation from an insurance company following a car accident and an intermediary, such as a court, which will decide whether the individual is to receive compensation. Both parties invest resources in obtaining evidence to prove their case while only the claimant knows his real situation. If the individual has been seriously injured in the accident then it will be easier for him to prove his case since for every unit of resources invested (to prove his case), he will have a higher probability of winning. On the other hand, if he is only lightly injured, it will be harder for him to prove his case and each unit of resources invested will have a lower return. In this case, the information regarding the individual's real state is private and known only to him. ${ }^{2}$ In the rentseeking literature, it has been established that asymmetry between the contestants reduces wasteful lobbying efforts. The asymmetry can be in terms of the lobbying capabilities, wealth endowments, attitudes toward risk or rent valuations of the contestants (see, for example, Allard (1988), Baik (1994), Epstein and Nitzan (2002, 2007), Gradstein (1994) and Nitzan (1994)).

The analysis of situations in which players value the prizes differently and their values are private information can be found in the economic literature. Nti (1999)

\footnotetext{
${ }^{2}$ On the topic of rent seeking with complete information in litigation and legal battles, see, for example, Hirshleifer and Osborne (2001), Farmer and Pecorino (1999) and Froeb and Kobayashi (1996).
} 
allows players to have different values but assumes that they are known. Malueg and Yates (2003), on the other hand, determine the Bayesian Nash equilibrium in a rentseeking contest in which the players' valuations of the prize are private information and determine the conditions under which the equilibrium exists. Wärneryd (2003) considers a two-player contest for a prize of common but uncertain value. For settings in which one player knows the value of the prize, while the other knows only its prior distribution, he provides conditions for a situation in which the uninformed agent is ex-ante strictly more likely to win the prize than the informed agent. In the special case of the Tullock contest, equilibrium expenditures are lower under asymmetric information than when either both agents are informed or neither agent is informed.

Hurley and Shogren (1998a) consider a model in which players value the stakes differently and there is one-sided private information, i.e. one player does not know the other's value. They investigate how changes in the nature of the one-sided information asymmetry affect investment levels in the contest and show that the results are a function of the level of information uncertainty. In a different paper, Hurley and Shogren (1998b) consider a model in which both players' values are private information and analyze the equilibrium numerically. They show that if the values (stakes) of the contestants are identical then rent dissipation is higher in the complete information contest than in the one-sided asymmetric information contest. This paper extends the literature to any size of stakes and compares the Bayesian Nash equilibrium outcome of the one-sided private information contest to the outcomes of a contest in which both players know the abilities of all the players. In our paper we show conditions under which uncertainty increases both the investment of the uninformed player and the contest's rent dissipation.

Clark (1997) considers a similar type of question to the one we present and examines a form of the Tullock imperfectly discriminating rent-seeking game in which the contestants are uncertain about the value of a bias parameter in the probability of winning function. Beliefs about this unknown parameter are not constrained to be static. He considers two methods by which the players' prior beliefs on this parameter can be updated. First, he allows for information to emerge by allowing the game to be played twice where the outcome of the first game is known before the second begins. The identity of the winner in the first contest represents information that emerges endogenously and which can be used to revise beliefs on the 
unknown bias parameter. Second, information can be produced outside the model by an external agency, which gives rise to exogenous learning.

In this paper, we consider a different one-sided private information problem. In the Bayesian Nash equilibrium, one player possesses information regarding his own ability and that of his opponent, while the other player only knows his own ability. We compare this contest to the case of fully-informed players, where each player knows his own ability and that of his opponent. The comparison is important in understanding to what extent the asymmetry affects the players. Would it be optimal for a central planner to invest resources to reduce the asymmetry between the players in order to minimize the waste of resources or to increase social welfare? In order to answer such questions it is important to compare the outcome under full information with that under information asymmetry. We start by presenting a case in which the informed player's ability can be one of two types and derive conditions under which the uninformed player invests more (or less) effort in the one-sided private information contest than in a complete information contest (Result 1). We also derive conditions under which the expected rent dissipation in a contest with one-sided private information is larger (or smaller) than in a fully-informed contest (Result 2). While it would appear at first glance that uncertainty may be an advantage to the informed player, we show general conditions under which incomplete information may in fact be harmful to him (Result 3). Surprisingly, we show that this condition is independent of the probability assigned by the uninformed player to the type of the informed player (or the proportion of each type in the population). Another question that we consider is whether ex-ante the informed player - before knowing his own type - prefers that the uninformed player knows his type and as such will play the game under full information (Result 4). We then turn to considering a two-stage game in which the informed player, in the first stage of the contest, declares his type (or does not declare) and in the second stage the players play according to the information available to them. We show that if the informed player can only tell the truth then the game will turn into a full information contest while if the informed player can lie, then a one-sided private information contest has meaning in this context (Result 5). We generalize Result 3 to allow for the informed player's ability to be any one of $N$ types (Result 6). The generalization enables us to show that in the case where one contestant has the same ability as the uninformed contestant, he will prefer a onesided private information contest (Result 6). 


\section{The model with two possible types of players}

We first consider the case in which the informed player's ability may be one of two types and then generalize the results to allow for the informed player's ability to have any one of $N$ possible values.

In this contest, there are two risk-neutral contestants who compete for a given prize. $^{3}$ Each contestant has the same valuation of the prize, which is equal to $n$. The players can have different abilities to translate their efforts into performance. In other words, a unit of effort invested by one player may have a different value in the determination of the winning probability than a unit invested by the other. In a onesided private information contest (i.e. an incomplete-information contest), the game proceeds as follows:

1. Stage I: In this stage, nature draws the type of player I (the informed player), such that with probability $p_{L}\left(0<p_{L}<1\right)$ he is chosen as type $L$ (the underdog) and with probability $p_{H}=1-p_{L}$ as type $H$ (the favorite). While player $I$ knows what type he is, the other player $U$ (the uninformed player) does not know the type of player $I$; however, it is common knowledge that he knows with probability $p_{L}$ that player $I$ is of type $L$ and with probability $p_{H}=1-p_{L}$ that he is of type $H$.

2. Stage II: Given the asymmetry in information described in Stage I between player $I$ and player $U$, they compete for a prize which, as mentioned, is equal to $n$. Player $I$ invests $x_{i}$ units of effort and has a valuation of $e_{i} x_{i}\left(e_{i}>0\right.$, $i=L, H)$ in the contest success function. At the same time, player $U$ invests $y$ units of effort in the contest and has a valuation of $y$ in the contest success function. Therefore, $U$ 's value can be treated as being 1 , i.e. $e_{U}=1$. We consider a Tullock (1980) contest success function with players that have asymmetric performance ability (see also Hirshleifer and Osborne, 2000, in the context of legal battles):

$$
\operatorname{Pr}_{x}=\frac{e_{i} x_{i}}{e_{i} x+y} \quad i=L, H
$$

\footnotetext{
3 This is the standard rent-seeking model (see Epstein and Nitzan (2006a, 2007)). For the micro foundations of a contest between interest groups, see Epstein and Nitzan (2006b).
} 
If neither player invests in the contest $\left(x_{i}=y=0\right)$, then each has an equal probability of winning $\left(\operatorname{Pr}_{x}=0.5\right)$. Expected net payoffs are given by:

$$
\begin{aligned}
& E\left(U_{U}\right)=\frac{p_{L} y}{e_{L} x_{L}+y} n+\frac{\left(1-p_{L}\right) y}{e_{H} x_{H}+y} n-y . \\
& E\left(U_{I i}\right)=\frac{e_{i} x_{i}}{e_{i} x_{i}+y} n-x_{i} \quad \forall i=L, H .
\end{aligned}
$$

The solution of this problem, which is presented below in Section 2.2, is a Bayesian Nash equilibrium. From this solution, we can derive the investment and expected utility of each player, given the asymmetry between player $I$ and player $U$.

By assumption, $0<e_{L} \neq e_{H}$, which is based on the idea that $H$ and $L$ are not identical. If they were, then we would have a game in which both players, $I$ and $U$, know their opponent's type with complete certainty. Therefore, in order for there to be uncertainty we must have two types of possibly informed players, each having a different valuation of their investment. Since the valuations are not identical one has a lower valuation of his efforts $(L)$ and the other a higher valuation $(H)$. Thus, without loss of generality, we can assume that $0<e_{L}<e_{H}$.

\subsection{A Benchmark: the case of certainty}

Consider the case in which each player knows his own ability (i.e. type) and that of his rival. This means that in Stage I, the two players, $I$ and $U$, know player $I$ 's type, as described in the previous section. For simplicity, we continue to use the same notation for the players $(I$ and $U$ ) as in the one-sided private information case. In other words, even though both players are fully informed, the notation $U$ will continue to indicate the uninformed player in the one-sided private information case.

Since player $I$ can be one of two types, $L$ or $H$, the players' expected net payoffs are given by: ${ }^{4}$

\footnotetext{
${ }^{4}$ A different way of looking at this situation is by considering that the value of winning for player $i$ is equal to $u_{i}$, and the value of losing to his opponent, player $j$, is equal to $v_{j}$. The expected prize of $i$ is equal to: $\operatorname{Pr}_{i} u_{i}+\operatorname{Pr}_{j} v_{i}, \mathrm{i} \neq \mathrm{j}$. Since $\operatorname{Pr}_{i}+\operatorname{Pr}_{j}=1$, the expected prize can be represented as $v_{i}+\operatorname{Pr}_{i} n_{i}$ where $n_{i}=\left(u_{i}-v_{i}\right)$ is the stake of player $i$ (the real benefit from winning the contest) (see Baik, 1999, Nti, 1999 and Epstein and Nitzan, 2006a, 2007). Since $v_{i}$ is a constant, it can be omitted from the calculations.
} 


$$
E\left(U_{U i}\right)=\frac{y_{i}}{e_{i} x_{i}+y_{i}} n-y_{i} \quad \forall i=L, H
$$

and

$$
E\left(U_{I i}\right)=\frac{e_{i} x_{i}}{e_{i} x_{i}+y_{i}} n-x_{i} \quad \forall i=L, H
$$

For player $U, y_{i}$ denotes his investment given the type of player $I, i=L, H$.

Each player determines his optimal investment in the contest in order to maximize his expected net payoff. Solving the first order conditions, ${ }^{5}$ we obtain that the Nash equilibrium investment of the players in the case of complete information is equal to:

$$
x_{i}^{*}=y_{i}^{*}=\frac{e_{i} n}{\left(e_{i}+1\right)^{2}} \quad i=L, H
$$

Expected rent dissipation is equal to:

$$
R D^{*}=x_{i}^{*}+y_{i}^{*}=\frac{2 e_{i} n}{\left(e_{i}+1\right)^{2}}
$$

and the expected net payoffs in equilibrium are equal to:

$$
E\left(U_{U i}^{*}\right)=\frac{n}{\left(e_{i}+1\right)^{2}} \quad i=L, H
$$

$$
E\left(U_{I i}^{*}\right)=n\left(\frac{e_{i}}{e_{i}+1}\right)^{2} \quad i=L, H
$$

Let us now consider which type of player $I$, i.e. type $L$ or type $H$, makes a larger investment in the contest (and accordingly player $U$ makes a larger investment as ${ }_{5} \frac{\partial E\left(U_{I i}\right)}{\partial x_{i}}=0$ and $\frac{\partial E\left(U_{U i}\right)}{\partial y_{i}}=0 \quad \forall i=L, H$. 
well). The answer depends on the two opposite effects of $e$ (the return on each unit of investment): as the value of $e$ increases, a player will invest more effort in the contest but at the same time player $I$ can then afford to invest less. The investment of player $I$ of type $L$ (the underdog) will be less than, equal to or greater than that of player $I$ of type $H$ (the favorite) if $x_{L}^{*}$ is less than, equal to or greater than $x_{H}^{*}$, respectively. In other words,

$$
x_{L}^{*}=x_{H}^{*} \text { and } y_{L}^{*}=y_{H}^{*} \text { if and only if } e_{H} e_{L} \stackrel{<}{>}=1
$$

In order to explain the intuition behind this condition, note that the value of player $U$ is equal to 1, i.e. $e_{U}=1$, which implies that the value of the rival $U$ in the success function is $e_{U} y=y$. Therefore, if $e_{i}=e_{L}<1\left(e_{i}=e_{H}>1\right)$, the effect of the rival's effort $L(H)$ on the probability function is lower (higher) than that of the rival $U$ and as a result the intensity of the competition is reduced (note that the intensity of the competition is also reduced in the case of $H$ ). Therefore, the two contestants, i.e. $U$ and $I(i=L, H)$, reduce their efforts. Thus, in comparison to $e_{U}=1$, the efforts of the two competitors, $L$ and $H$, are equal when $e_{H}$ "drifts" upward and $e_{L}$ "drifts" downward, such that symmetry is fulfilled, as given by $e_{H} e_{L}=1$. Therefore, if player $H$ (the favorite) is more "extreme" than player $L$ (the underdog), namely, $e_{H} e_{L}>1$, then player $H$ will invest less effort than player $L$ in the contest. We call this the asymmetry condition. This condition implies that relative to $e_{U}=1$, if $e_{H}$ "drifts" more than $e_{L}$, i.e. $e_{H} e_{L}>1$, then the intensity of competition between $U$ and $H$ will be less than that between $U$ and $L$ and therefore $x_{L}^{*}>x_{H}^{*}$ and $y_{L}^{*}>y_{H}^{*}$ (and of course vice versa).

\subsection{One-sided private information}

In this case, we examine the game described at the beginning of Section 2, in which both players know player $U$ 's type, while only player $I$ knows his own type. In a Bayesian Nash equilibrium, player $U$ will determine $y$ such that it maximizes his expected net payoff as defined in (2) and player $I$ will maximize his expected net payoff as defined in (3), given his actual type, which is either $L$ or $H$. 
As we will show, there may be two types of equilibrium. In the first, the effort invested by player $L$ is positive and in the second, it is zero. Let us start with the first case.

Case 1: $e_{H} e_{L}+\left(1-p_{L}\right)\left[e_{L}-\left(e_{H} e_{L}\right)^{0.5}\right]>0$.

Before we calculate the effort of each player, it is worthwhile explaining the intuition behind the fact that when this inequality is fulfilled, player's $L$ 's effort is positive. First, it can be seen that the sufficient conditions for this inequality being satisfied is that $p_{L}$ is relatively high or that $e_{H}$ (relative to $e_{L}$ ) is relatively distant from player $U$ 's value, $e_{U}=1\left(e_{H} e_{L} \geq 1\right)$. According to section 2.1 , in the case of certainty that player $U$ 's rival is $L$ ( $p_{L}=1$ ), the efforts of both players ( $U$ and $L$ ) will be positive, as can be seen from equation (6) for $i=L$, and therefore it is clear that if $p_{L}$ is relatively high player $L$ 's effort (and also that of player $U$ ) will be close to that given by equation (6) for $i=L$. In other words, player $L$ 's effort will still be positive. But what happens if $p_{H}$ is relatively high ( $p_{L}$ relatively low)? In this case, player $U$ relates to his rival, with a high probability, as player $H$ and therefore will invest effort that is close to that given by equation (6) for $i=H$. However, since $e_{H}$ (relative to $\left.e_{L}\right)$ is relatively distant from the value of player $U\left(e_{U}=1\right)$, then the intensity of competition between players $H$ and $U$ will be relatively low and therefore the effort of player $U$ (and also that of player $H$ ) will be relatively low. Thus, it will be worthwhile for player $L$ to invest positive effort. We now turn to describing the efforts of the players in this case.

Solving the first order condition, the investment made by player $U$ will be as follows (see Appendix 1):

$$
y^{* *}=e_{H} e_{L} n\left[\frac{p_{L} e_{H}^{0.5}+\left(1-p_{L}\right) e_{L}^{0.5}}{e_{H} e_{L}+p_{L} e_{H}+\left(1-p_{L}\right) e_{L}}\right]^{2}
$$

and the investment made by player $I$ will be equal to:

$$
x_{L}^{* *}=\frac{n\left\lfloor p_{L} e_{H}+\left(1-p_{L}\right)\left(e_{H} e_{L}\right)^{0.5}\left\{\left(e_{H} e_{L}+\left(1-p_{L}\right)\left[e_{L}-\left(e_{H} e_{L}\right)^{0.5}\right]\right\}\right.\right.}{\left[e_{H} e_{L}+p_{L} e_{H}+\left(1-p_{L}\right) e_{L}\right]^{2}},
$$




$$
x_{H}^{* * *}=\frac{n\left\lfloor p_{L}\left(e_{H} e_{L}\right)^{0.5}+\left(1-p_{L}\right) e_{L}\left\lfloor\left\{e_{H} e_{L}+p_{L}\left\lfloor e_{H}-\left(e_{H} e_{L}\right)^{0.5}\right]\right\}\right.\right.}{\left[e_{H} e_{L}+p_{L} e_{H}+\left(1-p_{L}\right) e_{L}\right]^{2}} .
$$

Since it is assumed that $e_{H} e_{L}+\left(1-p_{L}\right)\left[e_{L}-\left(e_{H} e_{L}\right)^{0.5}\right]>0, x_{L}^{* *}>0$ (for $x_{H}^{* * *}$ this is always true). The expected rent dissipation is equal to:

$$
R D^{* *}=p_{L} x_{L}^{* *}+\left(1-p_{L}\right) x_{H}^{* *}+y^{* * *}=2 e_{H} e_{L} n\left[\frac{p_{L} e_{H}^{0.5}+\left(1-p_{L}\right) e_{L}^{0.5}}{e_{H} e_{L}+p_{L} e_{H}+\left(1-p_{L}\right) e_{L}}\right]^{2}
$$

and the expected net payoffs in equilibrium are equal to:

$$
E\left(U_{U}^{* * *}\right)=n\left[p_{L} e_{H}+\left(1-p_{L}\right) e_{L}\left[\frac{p_{L} e_{H}^{0.5}+\left(1-p_{L}\right) e_{L}^{0.5}}{e_{H} e_{L}+p_{L} e_{H}+\left(1-p_{L}\right) e_{L}}\right]^{2}\right.
$$

$$
\begin{aligned}
& E\left(U_{I L}^{* *}\right)=n\left[\frac{e_{H} e_{L}+\left(1-p_{L}\right)\left[e_{L}-\left(e_{H} e_{L}\right)^{0.5}\right]}{e_{H} e_{L}+p_{L} e_{H}+\left(1-p_{L}\right) e_{L}}\right]^{2} \\
& E\left(U_{I H}^{* *}\right)=n\left[\frac{e_{H} e_{L}+p_{L}\left[e_{H}-\left(e_{H} e_{L}\right)^{0.5}\right]}{e_{H} e_{L}+p_{L} e_{H}+\left(1-p_{L}\right) e_{L}}\right]^{2} .
\end{aligned}
$$

Case 2: $e_{H} e_{L}+\left(1-p_{L}\right)\left[e_{L}-\left(e_{H} e_{L}\right)^{0.5}\right] \leq 0$.

Before we calculate the effort of each player, it is worthwhile explaining the intuition behind the fact that when this inequality holds, player $L$ 's effort is equal to zero. The two necessary conditions for this inequality to hold are that $p_{H}$ is relatively high $\left(p_{L}\right.$ relatively low) together with $e_{H}$ being relatively close (relative to $e_{L}$ ) to the value of player $U, e_{U}=1\left(e_{H} e_{L}<1\right)$. In this case, according to section 2.1, player $U$ relates to his rival, with a high probability, as player $H$ and therefore he will invest effort that is close to that given by equation (6) for $i=H$. However, since $e_{H}$ is relatively close to player $U$ 's value $\left(e_{U}=1\right)$, the intensity of competition is higher and therefore player 
$U$ 's effort (and also that of player $H$ ) will be high. Thus, it is worthwhile for player $L$ not to make any effort at all. We will now turn to describing the players' efforts in this case.

Under this assumption we obtain:

$$
y^{* * *}=\frac{\left(1-p_{L}\right)^{2} e_{H} n}{\left(e_{H}+1-p_{L}\right)^{2}}
$$

and the investment made by player $i=L, H$ is equal to:

$$
x_{L}^{* * * *}=0 \text { or } x_{H}^{* * *}=\frac{\left(1-p_{L}\right) e_{H} n}{\left(e_{H}+1-p_{L}\right)^{2}}
$$

The expected rent dissipation is equal to:

$$
R D^{* * * *}=p_{L} x_{L}^{* * * *}+\left(1-p_{L}\right) x_{H}^{* * * *}+y^{* * * *}=\frac{2\left(1-p_{L}\right)^{2} e_{H} n}{\left(e_{H}+1-p_{L}\right)^{2}}
$$

and the expected net payoffs in equilibrium are:

$$
E\left(U_{U}^{* * *}\right)=n\left[p_{L}+\frac{\left(1-p_{L}\right)^{3}}{\left(e_{H}+1-p_{L}\right)^{2}}\right]
$$

$$
E\left(U_{I L}^{* * *}\right)=0 \text { and } E\left(U_{I H}^{* * *}\right)=n\left(\frac{e_{H}}{e_{H}+1-p_{L}}\right)^{2} .
$$

Since $\left.e_{H} e_{L}+\left(1-p_{L}\right) \mid e_{L}-\left(e_{H} e_{L}\right)^{0.5}\right\rfloor>0$, it can be verified that when $e_{H} e_{L} \geq 1$ only case 1 holds; when $e_{H} e_{L}<1$ both cases are possible.

\subsection{The effort invested by the uninformed player}

We now compare the effort invested by the uninformed player in the following two situations: 
1. Complete information where both players know both types as given by equation (6).

2. Incomplete information, i.e. the one-sided private information case, where one player is the informed player and the other is the uninformed player as given by equations (11) and (18).

For the case in which the uninformed player invests more effort in the contest, we obtain the following result (see Appendix 2 for the calculations):

\section{Result 1}

1. If $e_{H} e_{L}>1$, the uninformed player invests less (more) effort in the one-sided private information contest than he would have against player $L(H)$ in a complete information contest or in other words, if $e_{H} e_{L}>1$ then $y_{L}^{*}>y^{* *}>y_{H}^{*}$.

2. If $e_{H} e_{L}<1$, the uninformed player invests less (more) effort in the one-sided private information contest than he would have against player $H(L)$ in a complete information contest or in other words, if $e_{H} e_{L}<1$ then $y_{H}^{*}>y^{* *}>y_{L}^{*}$.

We can explain the result for $e_{H} e_{L}>1$ using the following argument: ${ }^{6}$ In the complete information contest, when $e_{H} e_{L}>1$ player $U$ invests more against the underdog (player $L$ ) than against the favorite (player $H$ ) $\left(y_{L}^{*}>y_{H}^{*}\right)$, as shown above. Since in the incomplete information contest player $U$ invests the same amount against either type of player $I(L$ or $H)$ in both of the equilibria, it must be the case that he invests some "average" amount that would have been invested under complete information. Thus, $y_{L}^{*}>y^{* *}>y_{H}^{*}$.

\subsection{The expected rent dissipation}

By comparing the total expected investment (rent dissipation) in a full information contest to that in a one-sided private information contest, we obtain the following result (see Appendix 3 for proof):

\footnotetext{
${ }^{6}$ The explanation is similar for $e_{H} e_{L}<1$.
} 


\section{Result 2}

The expected rent dissipation in a contest with one-sided private information may be greater or smaller than that in a full information contest: If the informed contestant is of type $L(H)$ then the expected rent dissipation will be greater than the rent dissipation in the fully informed contest if and only if $e_{H} e_{L}<1\left(e_{H} e_{L}>1\right)$.

This result has the same flavor as the previous one and is based on the level of asymmetry between the players, i.e. whether the uninformed player is strong or weak. Thus, for example, if $e_{H} e_{L}<1$ then $e_{L}$ (relative to $e_{H}$ ) is distant from (and lower than) the value of player $U, e_{U}=1\left(e_{H} e_{L}<1\right)$. Therefore, under certainty, the intensity of competition will be low and therefore the total efforts of player $U$ and $L$ will be low relative to the total expected efforts of the players $U, L$ and $H$ in the case of uncertainty.

\subsection{Expected net payoffs}

Let us consider the case in which uncertainty may be a disadvantage to player $I$. In other words, the expected net payoff of player I under one-sided private information will be lower than his expected net payoff under full information. In order for this to be the case, we need to compare the expected net payoff of player $I$ in both cases. Under certainty, the expected net payoff of player $I$ is a function of his type and is given by equation (9). Under one-sided private information, player $I$ 's expected net payoff is given by equations (16), (17) and (22). The condition for player $I$ to be worse off as a result of his opponent (player $U$ ) not knowing his type is that his expected utility be higher under full information than under one-sided private information. ${ }^{7}$ In order for the situation of one-sided private information to be disadvantageous to the informed player, i.e. player $I$, it must hold that the expected utility under this condition is smaller than under certainty. The following result is therefore obtained (see Appendix 4 for the proof):

\footnotetext{
${ }^{7}$ Section 2.6 provides an answer to another question regarding the preference of player $I$ : would player $I$, before knowing his own type, ex-ante prefer that the uninformed player (player $U$ ) know his type and therefore play against him under full information or that he not know his type and play against him under one-sided private information (ex-ante behavior).
} 


\section{Result 3}

1. The condition for a player to be worse off as a result of his opponent not knowing his type, is independent of the probabilities $p_{L}$ and $p_{H}=1-p_{L}$.

2. The informed player of type $L(H)$ will prefer that the uninformed player be informed and will play against him in a game of certainty if and only if $e_{H} e_{L}<1\left(e_{H} e_{L}>1\right)$.

The second result states that when $e_{H} e_{L}<1$, if player $I$ is of type $L$ he would prefer that player $U$ know his type. The reason for this is based on Result 1 which describes player $U$ 's effort under uncertainty relative to full information when he is facing player $L$ or $H$. According to Result 1 if $e_{H} e_{L}<1$, then $y_{H}^{*}>y^{* *}>y_{L}^{*}$ (see the intuition behind this result following the presentation of Result 1) and player $U$ invests more effort against player $L$ in the one-sided private information contest than he would have in a complete information contest. Recall that the expected net payoff of player $I$ (of any type) decreases as the investment made by player $U$ (the uninformed player) increases. Thus, since player $U$ invests more effort against player $L$ in the one-sided private information contest than in the complete information contest, player $L$ would prefer player $U$ to know his type, which will reduce player $U$ 's investment in the contest and increase his own expected net payoff.

At first glance, the first result is surprising since it implies that the preferences of player $I$ (the informed player) for certainty over one-sided private information is independent of the probability assigned by player $U$ to player $I$ 's type (or the proportion of each type in the population). In contrast, given the explanation of Result 2, the intuition behind Result 3 part 1 becomes clear. In other words, when $e_{H} e_{L}<1$, then based on Result $1, y_{H}^{*}>y^{* * *}>y_{L}^{*}$ and it can be seen that player $U$ invests less effort in a situation of certainty when facing player $L$ than in a situation of uncertainty. This effort is independent of the probability assigned by player $U$ to the type of player $I$, since player $U$ "averages" his efforts between the two player types $(L$ and $H$ ) in a situation of uncertainty. The same type of arguments hold for $e_{H} e_{L}>1$ and the preference of player $H$. We can conclude from the above that in the case where player $L(H)$ has either the same ability as player $U$ or is more (less) efficient than player $U, e_{H}>e_{L} \geq 1\left(1 \geq e_{H}>e_{L}\right)$, player $H(L)$ would prefer player $U$ to know 
his type since this will increase the expected net profit of both the informed and the uninformed players.

\subsection{Ex-ante behavior}

In this section, we consider whether player $I$ (before knowing his own type) would exante prefer that the uninformed player (player $U$ ) know his type and as such play against him under full information or that he not know his type and play against him under one-sided private information.

When player $U$ knows player $I$ 's type, then according to equation (9) the ex-ante expected utility of player $I$ is equal to:

$$
p_{L} E\left(U_{I L}^{*}\right)+\left(1-p_{L}\right) E\left(U_{I H}^{*}\right)=p_{L} n\left(\frac{e_{L}}{e_{L}+1}\right)^{2}+\left(1-p_{L}\right) n\left(\frac{e_{H}}{e_{H}+1}\right)^{2}
$$

In contrast, when player $U$ does not know player I's type, there are two possibilities for the expected utility of player $I$ :

Case 1: when $\left.e_{H} e_{L}+\left(1-p_{L}\right) \mid e_{L}-\left(e_{H} e_{L}\right)^{0.5}\right\rfloor>0$, then from equations (16) and (17), the ex-ante expected utility of player $I$ equals,

$$
\begin{aligned}
& p_{L} E\left(U_{I L}^{* *}\right)+\left(1-p_{L}\right) E\left(U_{I H}^{* *}\right)= \\
& \text { (24) } p_{L} n\left[\frac{e_{H} e_{L}+\left(1-p_{L}\right)\left[e_{L}-\left(e_{H} e_{L}\right)^{0.5}\right.}{e_{H} e_{L}+p_{L} e_{H}+\left(1-p_{L}\right) e_{L}}\right]^{2}+\left(1-p_{L}\right) n\left[\frac{e_{H} e_{L}+p_{L}\left[e_{H}-\left(e_{H} e_{L}\right)^{0.5}\right.}{e_{H} e_{L}+p_{L} e_{H}+\left(1-p_{L}\right) e_{L}}\right]^{2}
\end{aligned}
$$

Case 2: when $\left.e_{H} e_{L}+\left(1-p_{L}\right) \mid e_{L}-\left(e_{H} e_{L}\right)^{0.5}\right\rfloor \leq 0$ then from equations (22), the ex-ante expected utility of player $I$ equals:

$$
p_{L} E\left(U_{I L}^{* * * * *}\right)+\left(1-p_{L}\right) E\left(U_{I H}^{* * * * *}\right)=\left(1-p_{L}\right) n\left(\frac{e_{H}}{e_{H}+1-p_{L}}\right)^{2}
$$

Player $I$ will prefer ex-ante that player $U$ not know his type if the expressions in (24) and (25) are greater than the expression in (23). Thus, in case 1: 


$$
\begin{aligned}
& p_{L} n\left[\frac{e_{H} e_{L}+\left(1-p_{L}\right)\left[e_{L}-\left(e_{H} e_{L}\right)^{0.5}\right.}{e_{H} e_{L}+p_{L} e_{H}+\left(1-p_{L}\right) e_{L}}\right]^{2}+\left(1-p_{L}\right) n\left[\frac{e_{H} e_{L}+p_{L}\left[e_{H}-\left(e_{H} e_{L}\right)^{0.5}\right]}{e_{H} e_{L}+p_{L} e_{H}+\left(1-p_{L}\right) e_{L}}\right]^{2} \\
& >p_{L} n\left(\frac{e_{L}}{e_{L}+1}\right)^{2}+\left(1-p_{L}\right) n\left(\frac{e_{H}}{e_{H}+1}\right)^{2}
\end{aligned}
$$

and in case 2:

$$
\left(1-p_{L}\right) n\left(\frac{e_{H}}{e_{H}+1-p_{L}}\right)^{2}>p_{L} n\left(\frac{e_{L}}{e_{L}+1}\right)^{2}+\left(1-p_{L}\right) n\left(\frac{e_{H}}{e_{H}+1}\right)^{2}
$$

\section{Result 4}

1. If $e_{H} e_{L}<1$, then player I will prefer ex-ante that the uninformed player not know his type.

2. If $e_{H} e_{L}=1$, then player I will be indifferent ex-ante to whether or not the uninformed player knows his type.

3. Player I will prefer ex-ante that the uninformed player knows his type if:

a. $1<e_{H} e_{L} \leq 4$ or

b. For every given value of $e_{H} e_{L}$ that fulfils $e_{H} e_{L}>4$, the difference between $e_{L}$ and $e_{H}$ is sufficiently large.

See Appendix 5 for proof.

It is worthwhile understanding the intuition behind Result 4. This will be done for each of its parts in turn:

Part 1 of Result $4\left(e_{H} e_{L}<1\right)$ : When Player $I$ knows he is of type $H$, then according to part 2 of Result 3 player $H$ prefers that player $U$ does not know who he is i.e. not to know his type and therefore it makes sense that ex ante, when $P_{L}$ is relatively small, this result will remain valid, as indeed was demonstrated. However, part 1 of Result 4 states that ex-ante player $I$ prefers that player $U$ not know who he is for any $P_{L}$, even when $P_{L} \rightarrow 1$ ! This appears to contradict the intuition behind part 2 of Result 3, according to which if player I knows with a high probability that he is type $L$ (when $P_{L} \rightarrow 1$ ), player $L$ will prefer that player $U$ knows who he is. In order to 
reconcile these two results for the cases in which $P_{L}$ is relatively large, we would first mention that according to the results obtained in (10) for the full information contest, when $e_{H} e_{L}<1$, the investment of player $U$ is larger when he faces player $H$ relative to when he faces player $L$, since the intensity of the competition when facing player $H$ is relatively high. This result also helps us to understand the following result obtained in an incomplete information contest: When $P_{L}$ rises, i.e. the probability that player $U$ is facing player $L$ rises, the investment of player $U$ declines (for $y^{* *}$ if $e_{H} e_{L}<1$ then $\frac{\partial y^{* *}}{\partial p_{L}}<0$ and for $y^{* * * *}, \frac{\partial y^{* * * *}}{\partial p_{L}}<0$ is always fulfilled). ${ }^{8}$ Clearly, the decrease in player $U$ 's investment as a result of the increase in $P_{L}$, is expressed as an increase in the utility of player $I$, whether he is player $L$ or player $H .{ }^{9}$ Given these insights, we can now explain the following two cases.

Case 1: $e_{H} e_{L}+\left(1-p_{L}\right)\left[e_{L}-\left(e_{H} e_{L}\right)^{0.5}\right\rfloor>0$.

We will make use of the following expression:

$$
\underbrace{p_{L}}_{1}[\underbrace{\left[E\left(U_{I L}^{* *}\right)-E\left(U_{I L}^{*}\right)\right]}_{2}+\underbrace{\left(1-p_{L}\right)}_{3} \underbrace{\left[E\left(U_{I H}^{* *}\right)-E\left(U_{I H}^{*}\right)\right]}_{4}
$$

${ }^{8}$ From the calculation of $\frac{\partial y^{* *}}{\partial p_{L}}$, we find that its sign is identical to that of the following expression: $\left(e_{H}^{0.5}-e_{L}^{0.5}\right)\left[e_{H} e_{L}+p_{L} e_{H}+\left(1-p_{L}\right) e_{L}\right]-\left(e_{H}-e_{L}\right)\left[p_{L} e_{H}^{0.5}+\left(1-p_{L}\right) e_{L}^{0.5}\right], \quad$ which after simplification becomes $\left(e_{H} e_{L}\right)^{0.5}\left(e_{H}^{0.5}-e_{L}^{0.5}\right)\left[\left(e_{H} e_{L}\right)^{0.5}-1\right]$. From here, if $e_{H} e_{L}<1$, then $\frac{\partial y^{* * *}}{\partial p_{L}}<0$, if $e_{H} e_{L}=1$ then $\frac{\partial y^{* *}}{\partial p_{L}}=0$ and if $e_{H} e_{L}>1$ then $\frac{\partial y^{* *}}{\partial p_{L}}>0$.

${ }^{9}$ Since player $I$ (whether he is $L$ or $H$ ) could have remained at the same level of investment (which is now non-optimal), which he chose prior to the increase in $P_{L}$, and to thus increase his probability of winning, since after the increase in $P_{L}$ the investment of player $U$ decreases. It is clear that if player $I$ 's probability of winning increases with no change in his investment, his utility increases. Essentially, player $I$ increases his utility even further, since he responds optimally by also changing his investment. Formally, the signs of $\frac{\partial E\left(U_{I L}^{* *}\right)}{\partial p_{L}}$ and $\frac{\partial E\left(U_{I H}^{* *}\right)}{\partial p_{L}}$ are dependent on the signs of $e_{H} e_{L}^{0.5}\left(e_{H}^{0.5}-e_{L}^{0.5}\right)\left[1-\left(e_{H} e_{L}\right)^{0.5}\right]$ and $e_{H}^{0.5} e_{L}\left(e_{H}^{0.5}-e_{L}^{0.5}\right)\left[1-\left(e_{H} e_{L}\right)^{0.5}\right]$, respectively. Therefore, if $e_{H} e_{L}<1$, then $\frac{\partial E\left(U_{l i}^{* *}\right)}{\partial p_{L}}>0$, if $e_{H} e_{L}=1$ then $\frac{\partial E\left(U_{I i}^{* *}\right)}{\partial p_{L}}=0$ and if $e_{H} e_{L}>1$ then $\frac{\partial E\left(U_{I i}^{* *}\right)}{\partial p_{L}}<0$, when $i=L, H$. 
which describes the gap in the ex-ante utility of player $I$ between the cases of incomplete and complete information and we will explain the intuition behind the fact that it is positive in cases where $P_{L}$ is high, including the case in which $P_{L} \rightarrow 1$.

If player $I$ knows that he is type $L$, he will prefer that player $U$ knows who he is (part 2 of Result 3: $E\left(U_{I L}^{* *}\right)<E\left(U_{I L}^{*}\right)$ ). According to the insights reached above (presented before case 1), as $P_{L}$ increases, the utility of player $L$ in the incomplete information contest increases and therefore the difference in the utility of player $L$ between the incomplete information contest and the complete information contest (where $P_{L}$ has no effect on utility) declines and when $P_{L} \rightarrow 1$ the difference approaches zero, i.e. $E\left(U_{I L}^{* * *}\right)-E\left(U_{I L}^{*}\right) \rightarrow 0^{-}$(part 2 in expression (28)). The reason for this is clear since when $P_{L} \rightarrow 1$ in the incomplete information contest player $U$ relates to player $I$ as player $L$ with a higher probability, as in the complete information contest. Therefore, in both contests, the strategies of the two players, $L$ and $U$, are almost identical and therefore the utility of player $L$ in both cases is as well.

In contrast, if player $I$ knows he is type $H$, he will prefer that player $U$ does not know his type (part 2 of Result 3: $E\left(U_{I H}^{* *}\right)>E\left(U_{I H}^{*}\right)$ ). Unlike in the previous explanation for player $L$, the difference in the utility of player $H$ between the incomplete and complete information contests is positive and does not approach zero, even when $P_{L} \rightarrow 1^{10}$, i.e. $E\left(U_{I H}^{* *}\right)-E\left(U_{I H}^{*}\right)>0$ (part 4 in expression (28)). The explanation for this is that under incomplete information player $U$ relates to player $I$ (even if he is $H$ ) as player $L$ with a high probability $\left(P_{L} \rightarrow 1\right)$. Therefore, player $U$ in the incomplete information contest invests almost the same amount as in the complete information contest when facing player $L$, i.e. $y^{* * *} \cong y_{L}^{*}=\frac{e_{L} n}{\left(e_{L}+1\right)^{2}}\left(\right.$ substituting $_{-} P_{L}=1$ in equation (11)), which is lower than in the case where player $U$ knows with certainty that he is facing player $H$. Therefore, the utility of player $H$ under incomplete information is higher, since player $U$ in this case invests less (since he estimates that he is facing player $L$ with a high probability) relative to under complete information

\footnotetext{
${ }^{10}$ When $P_{L} \rightarrow 1$, part 4 in expression (28) is positive and does not approach zero (since $e_{H} e_{L}<1$ ): $E\left(U_{I H}^{* *}\right)-E\left(U_{I H}^{*}\right)=n\left\langle\frac{e_{H}^{0.5}\left[1-\left(e_{H} e_{L}\right)^{0.5}\right]\left(e_{H}^{0.5}-e_{L}^{0.5}\right)}{e_{H}\left(e_{H}+1\right)\left(e_{L}+1\right)}\left\{\frac{e_{H}}{e_{H}+1}+\frac{e_{H} e_{L}+e_{H}^{0.5}\left(e_{H}^{0.5}-e_{L}^{0.5}\right)}{e_{H} e_{L}+e_{H}}\right\}\right\rangle>0$
} 
(in which player $U$ invests more since he knows with certainty that he is facing player $H)$.

From the aforementioned and from expression (28), it can be concluded that when $P_{L}$ increases, the utility of player $L$ under full information (is high and) approaches that under incomplete information and the difference in utilities for player $L$ between a complete and incomplete information contest approaches zero when $P_{L} \rightarrow 1$. On the other hand, the utility of player $H$ under complete information is lower and the difference in utilities for player $H$ remains positive, even in the case that $P_{L} \rightarrow 1$. Therefore, we obtain that ex-ante when moving from complete to incomplete information the "contribution" of player $H$ to the increase in utility is larger than the "contribution" of player $L$ to the decrease in utility. This result is described by expression (28), such that for player $H$ although the probability is lower it is multiplied by the positive difference in utilities (in expression (28), the produce of 3 and 4) and this product "overcomes" that of player $L$, whose probability is higher but is multiplied by a negligible difference in utilities (in expression (28), the product of 1 and 2).

Case 2: $e_{H} e_{L}+\left(1-p_{L}\right)\left[e_{L}-\left(e_{H} e_{L}\right)^{0.5}\right] \leq 0$.

We make use of the following expression:

$$
\underbrace{p_{L}}_{1}[\underbrace{\left[E\left(U_{I L}^{* * * *}\right)-E\left(U_{I L}^{*}\right)\right]}_{2}+\underbrace{\left(1-p_{L}\right)}_{3} \underbrace{\left[E\left(U_{I H}^{* * *}\right)-E\left(U_{I H}^{*}\right)\right]}_{4}
$$

which describes the difference in ex-ante utilities of player $I$ between incomplete and complete information in order to explain why it is positive in cases where $P_{L}$ is high, including the case in which $P_{L} \rightarrow 1$. The inequality $e_{H} e_{L}+\left(1-p_{L}\right)\left[e_{L}-\left(e_{H} e_{L}\right)^{0.5}\right] \leq 0$ is equivalent to $P_{L} \leq 1-\frac{e_{H} e_{L}^{0.5}}{e_{H}^{0.5}-e_{L}^{0.5}}$. It can be seen that when $P_{L} \rightarrow 1$, it must be that $e_{H} e_{L}^{0.5} \rightarrow 0$ and since $e_{H}>e_{L}$ this will happen if $e_{L} \rightarrow 0$ (otherwise we are in case
$1)$.
Therefore,

$$
E\left(U_{I L}^{* * * *}\right)-E\left(U_{I L}^{*}\right) \rightarrow-n\left(\frac{e_{L}}{e_{L}+1}\right)^{2} \rightarrow 0
$$

and 
$E\left(U_{I H}^{* * * *}\right)-E\left(U_{I H}^{*}\right) \rightarrow n\left[1-\left(\frac{e_{H}}{e_{H}+1}\right)^{2}\right]>0$ and as in case 1, we obtain that in the move from complete to incomplete information, the "contribution" of player $H$ to the increase in utility is greater than that of player $L$ to the decrease in utility. This is because even though the probability that player $I$ is type $H$ is lower, it is multiplied by a positive gap in utilities (in expression (29), 3 is multiplied by 4) and this product "overcomes" that of player $L$, for whom the probability is high but it is multiplied by a negligible gap in utilities (in expression (29), 1 is multiplied by 2).

Part 3 of Result 4: First, recall that when $e_{H} e_{L}>1$, only the results of case 1 are relevant, i.e. $\left.e_{H} e_{L}+\left(1-p_{L}\right) \mid e_{L}-\left(e_{H} e_{L}\right)^{0.5}\right\rfloor>0$, since it is the only possible case. We will first deal with the case of $1<e_{H} e_{L} \leq 4$. When player $I$ knows he is type $H$, then according to part 2 of Result 3, player $H$ prefers that player $U$ knows who he is and therefore it makes sense that when $P_{L}$ is relatively low and $1<e_{H} e_{L} \leq 4$ this result will remain valid also ex-ante, as was indeed obtained. Therefore we will explain the result for a relatively high $P_{L}$ and $1<e_{H} e_{L} \leq 4$, again using expression (28).

As in the explanation of case 1 above, if player $I$ knows he is type $L$ he will prefer that player $U$ does not know who he is (part 2 of Result 3); however, the difference in his utility between the incomplete and complete information contests decreases as $P_{L}$ increases. Moreover, when $P_{L} \rightarrow 1$, the difference in utilities of player $L$ (part 2 of expression (28)) between the contests approaches zero, i.e. $E\left(U_{I L}^{* *}\right)-E\left(U_{I L}^{*}\right) \rightarrow 0^{+}$. In contrast, if payer $I$ knows that he is type $H$, the difference in his utility between an incomplete and complete information contest is negative and does not approach zero, ${ }^{11}$ even when $P_{L} \rightarrow 1$, i.e. $E\left(U_{I H}^{* *}\right)-E\left(U_{I H}^{*}\right)<0$ (part 4 in expression (28)). This is because under incomplete information player $U$ relates to player $I$ with a high probability $\left(P_{L} \rightarrow 1\right)$ as player $L$ (even if he is $H$ ). Therefore, player $U$ in an incomplete information contest invests almost the same amount as in a

\footnotetext{
${ }^{11}$ When $P_{L} \rightarrow 1$, part 4 in expression (28) is negative and does not approach zero (since $e_{H} e_{L}>1$ ): $E\left(U_{I H}^{* *}\right)-E\left(U_{I H}^{*}\right)=n\left\langle\frac{e_{H}^{0.5}\left[1-\left(e_{H} e_{L}\right)^{0.5}\right]\left(e_{H}^{0.5}-e_{L}^{0.5}\right)}{e_{H}\left(e_{H}+1\right)\left(e_{L}+1\right)}\left\{\frac{e_{H}}{e_{H}+1}+\frac{e_{H} e_{L}+e_{H}^{0.5}\left(e_{H}^{0.5}-e_{L}^{0.5}\right)}{e_{H} e_{L}+e_{H}}\right\}\right\rangle<0$
} 
complete information contest when he faces player $L$, i.e. $y^{* *} \cong y_{L}^{*}=\frac{e_{L} n}{\left(e_{L}+1\right)^{2}}$ (substitution of $P_{L}=1$ in equation (11)), which is higher than in the case where player $U$ knows with certainty that he is facing player $H$. Therefore, the utility of player $H$ in an incomplete information contest is lower. This is because player $U$ invests more in this case since he estimates with a higher probability that he is facing player $L$ relative to complete information (in which player $U$ would invest less since he knows with certainty that he is facing player $H$ ). Thus, when $P_{L}$ increases, the utility of player $L$ in complete information (is lower and) approaches that of in an incomplete information contest and the difference between the utilities for player $L$ approaches zero when $P_{L} \rightarrow 1$. On the other hand, the utility of player $H$ under complete information is higher and the difference between the utilities for player $H$ remains positive, even in the case that $P_{L} \rightarrow 1$.

Therefore, when $e_{H} e_{L}$ is relatively "low" $\left(1<e_{H} e_{L} \leq 4\right)$ we obtain ex-ante that in the move from incomplete to complete information, the "contribution" of player $H$ to the increase in utility is larger than that of player $L$ to the decrease in utility. This result can be seen in expression (28) where although the probability for player $H$ is lower it is multiplied by a negative utility gap (in expression (28), 3 is multiplied by 4) and this product "overcomes" that of player $L$, whose probability, even though it is higher, is multiplied by a negligible utility gap (in expression (28), 1 is multiplied by 2). Although for relatively "large" $e_{H} e_{L}\left(e_{H} e_{L}>4\right)$ it is possible to obtain the opposite result in which player $I$ prefers that player $U$ does not know who he is, ${ }^{12}$ for a large enough difference between $e_{L}$ and $e_{H}$ we obtain that player $I$ will prefer that player $U$ knows his type. This can be explained as follows: First, for every given $e_{L}$ and $e_{H}$, the utility of player $H$ is higher than that of player $L$, whether in a complete information contest (equation (9)) or in an incomplete information contest (equations (16) and (17)). In addition, in the move from incomplete to complete information the utility of player $H$ increases and that of $L$ decreases, since $U$ "averages" his investment between the two levels of his investment in complete information (as

\footnotetext{
${ }^{12}$ Thus, for example, if $e_{H}=100, e_{L}=0.5, n=1$ and $P_{L}=0.5$, we obtain that the ex-ante expected utility of player $I$ in the case of incomplete information is higher than in the case of complete information: $p_{L} E\left(U_{I L}^{* *}\right)+\left(1-p_{L}\right) E\left(U_{I H}^{* *}\right)=0.5715>0.5457=p_{L} E\left(U_{I L}^{*}\right)+\left(1-p_{L}\right) E\left(U_{I H}^{*}\right)$.
} 
explained in part 1 of Result 1, i.e. $y_{L}^{*}>y^{* *}>y_{H}^{*}$ ). Now, for a given $e_{H} e_{L}$, if $e_{H}$ is sufficiently large and $e_{L}$ is sufficiently small, we obtain that ex-ante in the shift from incomplete to complete information the "contribution" of player $H$ to the increase in utility is higher than that of player $L$ to the decrease in utility and therefore player $I$ ex-ante prefers that player $U$ knows who he is. Note that this result is not symmetric to the result obtained when $e_{H} e_{L}<1$, where in any case player $I$ ex-ante prefers that player $U$ does not know who he is, since the difference in that case is "limited" relative to the case in which $e_{H} e_{L}>4$, where the difference between the values of the players can be larger.

\subsection{Two-Stage Contest}

Another question worth examining is whether conditions exist under which the contest under uncertainty becomes a contest of certainty, in which the type of player $I$ is revealed to player $U$.

Assume that in the first stage of the contest player $I$ can decide whether or not to reveal his type and in the second stage the players play according to the information they possess. Assume that $e_{H} e_{L}<1$ (as a result of symmetry, the same type of arguments can be presented for $e_{H} e_{L}>1$ ). From part 2 of Result 3, the following situations can arise:

1. Since player $L$ prefers player $U$ to know his type, he will reveal his type as $L$ and since player $H$ prefers player $U$ not to know his type he will not reveal his type.

2. From 1, player $U$ will know player $I$ 's type with certainty since if player $I$ reveals his type then it must be $L$ and if he does not then it must be $H$. This is known to player $H$ and as such they will be playing a contest with complete information.

According to the following result, if player $I$ can lie in the second stage of the contest, then claim 2 above is not possible in equilibrium and therefore in the contest described above as a two-stage contest the results under asymmetric information are not redundant. 


\section{Result 5}

In a two-stage contest in which player I can reveal information to player $U$ regarding his own type in the first stage:

1. If player I can only reveal true information about himself, then the contest becomes a complete information contest with player $U$ knowing the type of player $I$.

2. If player I can lie in the first stage, then there is no equilibrium in which player $U$ can reveal the type of player I in the first stage.

Part 1 of Result 5 is derived directly from the contest presented above. In order to prove part 2 of Result 5, we must show that it is optimal for player $I$ of type $H$ to declare in the first stage that he is of type $L$ even though he is of type $H$. We show this in Appendix 6.

The intuition behind this can be seen from the results described in (10), according to which player $H$ declares himself to be player $L$ and player $U$ relates to him in that way also and plays against him accordingly. Thus, player $U$ invests less than he would have if he had known that he is facing player $H$ (according to (10), if $e_{H} e_{L}<1$, then $\left.y_{L}^{*}<y_{H}^{*}\right)$. Therefore, the utility of player $H$ will be higher if he declares himself as being type $L$. Thus, player $U$ cannot know player $I$ 's type from his declaration in the first stage, since according to the explanation above player $I$ will declare that he is type $L$ in the first stage of the contest, whether he is $L$ or $H$ (if $\left.e_{H} e_{L}<1\right)$. This means that in the two-stage contest if player $I$ can lie in the first stage, then there is no equilibrium in which player I's type is revealed in that stage.

The idea of revealing one's type is not new. Raith (1996) dealt with a similar problem when he considered the incentive of an oligopolist to share private information regarding stochastic demand or stochastic costs. He presented a general model which encompasses virtually all models of the existing literature on information. Within this overall framework, he shows that in contrast to the apparent inconclusiveness of previous results some simple principles determining the incentives to share information can be deduced. One of the main incentives for firms to exchange information is to improve their information about market conditions, which is valid only as far as information about own demand or cost is involved. The incentives to reveal information are as follows: (1) enabling rivals to acquire better 
knowledge of their respective profit functions leads to a higher correlation of strategies, the profitability of which is determined by the slope of the reaction curves; and (2) enabling rivals to acquire better knowledge of one's own profit function is always profitable.

In some sense, our model deals with a similar situation. Revealing one's type may well increase the profitability of the informed player. However, this will only occur if the rival, i.e. the uninformed player, receives true information. If the informed player can lie, the uninformed player will never know if he is telling the truth or not and as such the information will never be revealed.

\section{3. $N$ possible types of players}

We now generalize the results to $N$ possible types of players under an interior equilibrium. Consider the case where, with probability $P_{i,}$, player $I$ has a valuation of his investment at a level of $e_{i}$ for $i=1,2, \ldots, N$ such that $\sum_{i=1}^{N} P_{i}=1$. Without loss of generality, assume that $e_{1}<e_{2}<\ldots<e_{N-1}<e_{N}$. The expected net payoff of player $U$ becomes:

$$
E\left(U_{U}\right)=\sum_{i=1}^{N} \frac{p_{i} y}{e_{i} x_{i}+y} n-y \text { subject to } \sum_{i=1}^{N} P_{i}=1
$$

and the expected net payoff of player $I$ is equal to:

$$
E\left(U_{I i}\right)=\frac{e_{i} x_{i}}{e_{i} x_{i}+y} n-x_{i} \quad \forall i=1,2, \ldots, N
$$

In a Bayesian Nash equilibrium, player $U$ will determine $y$ such that it maximizes his expected net payoff as defined in (30) and player $I$ will maximize his expected net payoff as defined in (31) given his actual type, $i=1,2, \ldots, N$. In this case, the following result is obtained (see Appendix 7 for proof): 


\section{Result 6}

1. The informed player of type 1 (player of type $N$ ) will prefer that the uninformed player be informed and play against him in a game of certainty if $e_{N} e_{1}<1$ $\left(e_{N} e_{1}>1\right)$. This condition is independent of the probabilities $p_{i}, i=1,2, \ldots, N$.

2. In the case where there exists a possibility that one of the players has an investment valuation level of $e=1$, then this individual will always prefer to compete in a one-sided private information contest.

These results generalize the findings presented in the previous section of the paper, which provide the general conditions under which the extreme type of player will prefer a game under certainty to a one-sided private information contest. Note that the intuition behind this result is identical to that presented for Result 3 with two players. Moreover, in the case where one of the individuals may have the same ability as the uninformed contestant, he will prefer a one-sided private information contest. Thus, in the case of $N=3$, such that $e_{1}<e_{2}=1<e_{3}$ : player 1 (player 3) will prefer a game of complete information if $e_{3} e_{1}<1 \quad\left(e_{3} e_{1}>1\right)$ and player 2 will always prefer a onesided private information contest to a game with full information.

In order to understand this result (for any number of players $N$ ), we denote the player whose value is 1 as $A$, i.e. $e_{A}=1$. Note that in this case, the values of players $U$ and $A$ are equal, i.e. $e_{A}=e_{U}=1$. Under complete information, the intensity of competition is maximized and therefore the efforts of both players ( $U$ and $A$ ) are the highest relative to the efforts of any other player who competes against $U$. This is because the intensity of competition between $U$ and any other player whose value is different from 1 would be lower. Thus, under partial information, player $U$ 'averages' his efforts and as a result they are low relative to the maximal effort that he would have invested against player $A$ under complete information. We obtain therefore that player $U$ under incomplete information makes less of an effort and therefore player $A$ 's utility is increased. 


\section{Conclusion}

In this paper, we have considered a Bayesian Nash contest of incomplete information in which contestants have asymmetric abilities and compare it to the results obtained under a complete information framework. The considered case is a situation of onesided private information in which one player knows the abilities of both players while the other only knows his own ability. We first examined the case for two types of ability and then generalized the results to allow for the informed player's ability to be any one of $N$ possible values.

The various outcomes were compared for two diverse situations: common knowledge of players' abilities and one-sided private information. The outcomes examined include the expenditure of the uninformed player, the expected rent dissipation and the expected payoff of the informed player in both types of contests. It was shown that the comparison of these measurements in the two contests depends on the asymmetry condition, i.e., whether the product of the ability coefficients, $e_{L}$ and $e_{H}$, is greater, smaller or equal to one. Moreover, the results do not depend on the probability assigned by the uninformed player to the type of player he is playing against.

While one would imagine uncertainty to be an advantage for the informed player, we show general conditions under which incomplete information may be harmful to him and will increase the rent dissipation of the contest. More specifically, if $e_{H} e_{L}<1\left(e_{H} e_{L}>1\right)$ and the informed player is of type $L(H)$, he would prefer that the uninformed player know his type and compete with him in a contest with complete information, where each player knows the ability of the other. Thus, the informed player is worse off in this situation than when his competitor is informed of his type.

We then presented conditions that determine when player I prefers ex-ante, i.e. before knowing his own type, that the uninformed player (player $U$ ) know his type and as such will play against him under complete information or that he not know his type and will play against him under one-sided private information. In addition, we discussed a two-stage game in which player $I$ in the first stage, can decide whether or not to reveal his type and in the second stage the game is played according to the information available. We showed that if the informed player can only tell the truth in the first stage, then the game will turn into a complete information contest while if the 
informed player can lie, then the uninformed player will never know if the informed player is telling the truth. In this last case, there is no equilibrium in a two-stage contest in which the type of player $I$ is revealed in the first stage.

The results were generalized to $N$ types of individuals, which made it possible to show that in the case where one of the individuals may have the same ability as the uninformed contestant, he would prefer a one-sided private information contest. 


\section{References}

Allard, R.J. (1988). Rent seeking with non-identical players. Public Choice, 57: 3-14.

Baik, K.H. (1994). Winner-help-loser group formation in rent-seeking contests. Economics and Politics, 6, 147-162.

Clark D.J. (1997). Learning the Structure of a Simple Rent-Seeking Game, Public Choice 93, 119-130

Epstein G.S. and Nitzan, S. (2002). Asymmetry and Corrective Public Policy in Contests. Public Choice, 113(1): 231-240.

Epstein G.S. and Nitzan, S. (2006a). Effort and Performance in Public Policy Contests. Journal of Public Economic Theory, 8(2) 265-282.

Epstein G.S. and Nitzan, S. (2006b). The Politics of Randomness. Social Choice and Welfare, 27(2): 423-433.

Epstein G.S. and Nitzan S. (2007). Endogenous Public Policy and Contests, Springer.

Farmer, A. and Pecorino, P. (1999). Legal Expenditure as a Rent Seeking Game. Public Choice, 100: 271-288.

Froeb, L.M. and Kobayashi, B.H. (1996). Native, Biased yet Bayesian: Can Juries Interpret Selectivity Produced Evidence?. The Journal of Law, Economics and Organization, V12 N1: 257-276.

Gradstein, M. (1994). Intensity of competition, entry and entry deterrence in rentseeking contests. Economics and Politics, 7: 79-91.

Hirshleifer, J. and Osborne, E. (2000). Truth, Effort, and the Legal Battle. Public Choice, 108:169-195.

Hurley, T. and Shogren, J. (1998a). Effort levels in a Cournot Nash contest with asymmetric information. Journal of Public Economics, 69: 195-210.

Hurley, T. and Shogren, J. (1998b). Asymmetric information contests. European Journal of Political Economy, 14: 645-665.

Malueg D.A. and Yates, A.J. (2004). Rent seeking with private values. Public Choice, 119: $161-178$.

Nitzan, S. (1994). Modelling rent-seeking contests. European Journal of Political Economy, 10(1): 41-60.

Nti, K. (1999). Rent-seeking with asymmetric valuations. Public Choice, 98: 415430.

Raith M. (1996). A General Model of Information Sharing in Oligopoly. Journal of Economic Theory, 71: 260-288 
Tullock, G. (1980). Efficient rent-seeking. In Buchanan, J.M., Tollison, R.D. and Tullock, G., Towards a Theory of the Rent-Seeking Society, College Station, TX: Texas A. and M. University Press: 97-112.

Wärneryd, K. (2003). Information in conflicts. Journal of Economic Theory, 10(1), 121-136. 


\section{Appendix 1}

Case 1: $e_{H} e_{L}+\left(1-p_{L}\right)\left[e_{L}-\left(e_{H} e_{L}\right)^{0.5}\right]>0$.

The first order conditions $\left(\frac{\partial E\left(U_{I i}\right)}{\partial x_{i}}=0 \quad \forall i=L, H\right.$ and $\left.\frac{\partial E\left(U_{U}\right)}{\partial y}=0\right) 13$ are:

$$
\begin{aligned}
& \text { for } i=L \quad \frac{e_{L} y n}{\left(e_{L} x_{L}+y\right)^{2}}-1=0 \\
& \text { for } i=H \quad \frac{e_{H} y n}{\left(e_{H} x_{H}+y\right)^{2}}-1=0 \\
& \frac{p_{L} e_{L} x_{L} n}{\left(e_{L} x_{L}+y\right)^{2}}+\frac{\left(1-p_{L}\right) e_{H} x_{H} n}{\left(e_{H} x_{H}+y\right)^{2}}-1=0
\end{aligned}
$$

and, after rearranging:

$$
\begin{gathered}
y^{* * *}=e_{H} e_{L} n\left[\frac{p_{L} e_{H}^{0.5}+\left(1-p_{L}\right) e_{L}^{0.5}}{e_{H} e_{L}+p_{L} e_{H}+\left(1-p_{L}\right) e_{L}}\right]^{2} \\
x_{H}^{* *}=\frac{n\left\lfloor p_{L}\left(e_{H} e_{L}\right)^{0.5}+\left(1-p_{L}\right) e_{L}\right]\left[e_{H} e_{L}+p_{L}\left\lfloor e_{H}-\left(e_{H} e_{L}\right)^{0.5}\right]\right\}}{\left[e_{H} e_{L}+p_{L} e_{H}+\left(1-p_{L}\right) e_{L}\right]^{2}} \\
x_{L}^{* * *}=\frac{n\left\lfloor p_{L} e_{H}+\left(1-p_{L}\right)\left(e_{H} e_{L}\right)^{0.5}\right]\left\{e_{H} e_{L}+\left(1-p_{L}\right)\left[e_{L}-\left(e_{H} e_{L}\right)^{0.5}\right]\right\}}{\left[e_{H} e_{L}+p_{L} e_{H}+\left(1-p_{L}\right) e_{L}\right]^{2}} .
\end{gathered}
$$

Since $e_{H} e_{L}+\left(1-p_{L}\right)\left[e_{L}-\left(e_{H} e_{L}\right)^{0.5}\right]>0$ we obtain that $x_{L}^{* *}>0$.

Case 2: $e_{H} e_{L}+\left(1-p_{L}\right)\left[e_{L}-\left(e_{H} e_{L}\right)^{0.5}\right] \leq 0$.

Given that $e_{H} e_{L}+\left(1-p_{L}\right)\left[e_{L}-\left(e_{H} e_{L}\right)^{0.5}\right] \leq 0$, the equilibrium stated in case 1 no longer holds. Thus, there is no Bayesian Nash equilibrium under which $x_{L}>0$.

In order to calculate the equilibrium strategies, we assume that $x_{L}=0$ holds in equilibrium, an assumption which will be shown below to indeed hold. Therefore, we substitute $x_{L}=0$ in equations (2) and (3) to obtain the utility of player $U$ and of player $I$ (who is of type $H$ ):

$$
E\left(U_{U}\right)=p_{L} n+\frac{\left(1-p_{L}\right) y}{e_{H} x_{H}+y} n-y \text { and }, E\left(U_{I H}\right)=\frac{e_{H} x_{H}}{e_{H} x_{H}+y} n-x_{H} .
$$

\footnotetext{
${ }^{13}$ It can be verified that the second order conditions are satisfied.
} 
The first order conditions to find $x_{H}$ and $y$ are given by $\frac{\partial E\left(U_{U}\right)}{\partial y}=\frac{\left(1-p_{L}\right) e_{H} x_{H}}{\left(e_{H} x_{H}+y\right)^{2}} n-1=0 \quad$ and $\quad \frac{\partial E\left(U_{I H}\right)}{\partial x_{H}}=\frac{e_{H} y}{\left(e_{H} x_{H}+y\right)^{2}} n-1=0, \quad$ and therefore the optimal values are $x_{H}^{* * * *}=\frac{\left(1-p_{L}\right) e_{H} n}{\left(e_{H}+1-p_{L}\right)^{2}}$ and $y^{* * * * *}=\frac{\left(1-p_{L}\right)^{2} e_{H} n}{\left(e_{H}+1-p_{L}\right)^{2}}$. We will now show that given $y^{* * *}$, the assumption that $x_{L}=0$ in equilibrium is the correct one. To this end, we differentiate $E\left(U_{I L}\right)=\frac{e_{L} x_{L}}{e_{L} x_{L}+y} n-x_{L}$ with respect to $x_{L}$ to obtain:

$$
\frac{\partial E\left(U_{I L}\right)}{\partial x_{L}}=\frac{e_{L} y n}{\left(e_{L} x_{L}+y\right)^{2}}-1
$$

We will now show that by substituting $y^{* * *}$ and $x_{L}=0$ in (A4) we obtain $\frac{\partial E\left(U_{I L}\right)}{\partial x_{L}} \leq 0$ and as a result $x_{L}^{* * * *}=0$. We substitute $y^{* * *}$ and $x_{L}=0$ in (A4) to obtain:

$$
\frac{\partial E\left(U_{I L}\right)}{\partial x_{L}}=\frac{e_{L} n}{y^{* * * *}}-1=\frac{e_{L} n}{\frac{\left(1-p_{L}\right)^{2} e_{H} n}{\left(e_{H}+1-p_{L}\right)^{2}}}-1=\frac{e_{L}\left(e_{H}+1-p_{L}\right)^{2}-\left(1-p_{L}\right)^{2} e_{H}}{\left(1-p_{L}\right)^{2} e_{H}}
$$

We will show that the denominator in the last term is not positive, thus completing the proof. In other words, we need to show that:

$$
e_{L}\left(e_{H}+1-p_{L}\right)^{2} \leq\left(1-p_{L}\right)^{2} e_{H}
$$

or

$$
e_{H} e_{L}\left(e_{H}+1-p_{L}\right)^{2} \leq\left(1-p_{L}\right)^{2} e_{H}^{2}
$$

Taking the root of both sides and simplifying yields:

$$
\left(e_{H} e_{L}\right)^{0.5}\left(e_{H}+1-p_{L}\right) \leq\left(1-p_{L}\right) e_{H}
$$

Multiplying both sides by $\left(\frac{e_{L}}{e_{H}}\right)^{0.5}$ gives:

$$
e_{H} e_{L}+\left(1-p_{L}\right) e_{L} \leq\left(1-p_{L}\right)\left(e_{H} e_{L}\right)^{0.5}
$$

or

$$
e_{H} e_{L}+\left(1-p_{L}\right)\left[e_{L}-\left(e_{H} e_{L}\right)^{0.5}\right] \leq 0
$$

where the last expression holds by assumption. 
Thus, if $e_{H} e_{L}+\left(1-p_{L}\right)\left[e_{L}-\left(e_{H} e_{L}\right)^{0.5}\right] \leq 0$ then equilibrium will be at $x_{L}^{* * * *}=0$, $x_{H}^{* * * *}=\frac{\left(1-p_{L}\right) e_{H} n}{\left(e_{H}+1-p_{L}\right)^{2}}$ and $y^{* * * *}=\frac{\left(1-p_{L}\right)^{2} e_{H} n}{\left(e_{H}+1-p_{L}\right)^{2}}$.

\section{Appendix 2 - Proof of Result 1}

Case $1: e_{H} e_{L}+\left(1-p_{L}\right)\left[e_{L}-\left(e_{H} e_{L}\right)^{0.5}\right]>0$.

In the case where the informed player is of type $L$, the investment of the uninformed player under uncertainty $\left(y^{* *}\right)$ will be smaller than that under certainty $\left(y_{L}^{*}\right)$ if:

$$
y^{* * *}=e_{H} e_{L} n\left[\frac{p_{L} e_{H}^{0.5}+\left(1-p_{L}\right) e_{L}^{0.5}}{e_{H} e_{L}+p_{L} e_{H}+\left(1-p_{L}\right) e_{L}}\right]^{2}<\frac{e_{L} n}{\left(e_{L}+1\right)^{2}}=y_{L}^{*}
$$

or

$$
\frac{p_{L} e_{H}+\left(1-p_{L}\right)\left(e_{H} e_{L}\right)^{0.5}}{e_{H} e_{L}+p_{L} e_{H}+\left(1-p_{L}\right) e_{L}}<\frac{1}{e_{L}+1}
$$

or

$$
\left(1-p_{L}\right) e_{H}^{0.5} e_{L}^{1.5}+\left(1-p_{L}\right)\left(e_{H} e_{L}\right)^{0.5}<\left(1-p_{L}\right) e_{H} e_{L}+\left(1-p_{L}\right) e_{L} .
$$

Dividing both sides by $\left(1-p_{L}\right)$ yields:

$$
e_{H}^{0.5} e_{L}^{1.5}+\left(e_{H} e_{L}\right)^{0.5}<e_{H} e_{L}+e_{L}
$$

or

$$
e_{L}^{0.5}\left[\left(e_{H} e_{L}\right)^{0.5}-1\right]\left(e_{H}^{0.5}-e_{L}^{0.5}\right)>0 .
$$

Since $e_{L}<e_{H}$, inequality (A4) holds if and only if $e_{H} e_{L}>1$.

In a similar manner, it can be verified that if the informed player is of type $H$, the investment of the uninformed player under uncertainty will be smaller than under certainty if and only if $e_{H} e_{L}<1$.

Case 2: $e_{H} e_{L}+\left(1-p_{L}\right)\left[e_{L}-\left(e_{H} e_{L}\right)^{0.5}\right] \leq 0 . .^{14}$

In the case where the informed player is of type $L$ the investment of the uninformed player under uncertainty $\left(y^{* * * *}\right)$ will be larger than under certainty $\left(y_{L}^{*}\right)$. To prove this, it needs to be shown that:

\footnotetext{
${ }^{14}$ Notice that this case is possible only if $e_{H} e_{L}<1$.
} 


$$
y^{* * * * *}=\frac{\left(1-p_{L}\right)^{2} e_{H} n}{\left(e_{H}+1-p_{L}\right)^{2}}>\frac{e_{L} n}{\left(e_{L}+1\right)^{2}}=y_{L}^{*} .
$$

Multiplying both sides by $e_{H}$, taking the square root and rewriting, we obtain that $y^{* * * *}>y_{L}^{*}$ if $\left(e_{H} e_{L}\right)^{0.5}\left(e_{H}+1-p_{L}\right)-\left(1-p_{L}\right) e_{H}\left(e_{L}+1\right)<0$. The value of the LHS of the inequality is smaller than $\left(e_{H} e_{L}\right)^{0.5}\left(e_{H}+1-p_{L}\right)-\left(1-p_{L}\right) e_{H}$. According to Appendix 1, when $e_{H} e_{L}+\left(1-p_{L}\right)\left[e_{L}-\left(e_{H} e_{L}\right)^{0.5}\right] \leq 0$ the last expression is negative and therefore $y^{* * * *}>y_{L}^{*}$.

In a similar manner, it can be verified, that if the informed player is of type $H$, the investment of the uninformed player under uncertainty will be smaller than under certainty.

\section{Appendix 3 - Proof of Result 2}

Case 1: $e_{H} e_{L}+\left(1-p_{L}\right)\left[e_{L}-\left(e_{H} e_{L}\right)^{0.5}\right]>0$.

The expected rent dissipation in the contest with one-sided private information, which is given by equation (14), is greater than that in the case of certainty, which is given by equation (7), if:

$$
R D^{*}=\frac{2 e_{i} n}{\left(e_{i}+1\right)^{2}}<2 e_{H} e_{L} n\left[\frac{p_{L} e_{H}^{0.5}+\left(1-p_{L}\right) e_{L}^{0.5}}{e_{H} e_{L}+p_{L} e_{H}+\left(1-p_{L}\right) e_{L}}\right]^{2}=R D^{* *}
$$

For $i=L$, inequality (A6) holds if:

$$
\frac{2 e_{L} n}{\left(e_{L}+1\right)^{2}}<2 e_{H} e_{L} n\left[\frac{p_{L} e_{H}^{0.5}+\left(1-p_{L}\right) e_{L}^{0.5}}{e_{H} e_{L}+p_{L} e_{H}+\left(1-p_{L}\right) e_{L}}\right]^{2}
$$

or

$$
\frac{1}{e_{L}+1}<\frac{p_{L} e_{H}+\left(1-p_{L}\right)\left(e_{H} e_{L}\right)^{0.5}}{e_{H} e_{L}+p_{L} e_{H}+\left(1-p_{L}\right) e_{L}}
$$

or

$$
\left(1-p_{L}\right) e_{H} e_{L}+\left(1-p_{L}\right) e_{L}<\left(1-p_{L}\right) e_{H}^{0.5} e_{L}^{1.5}+\left(1-p_{L}\right)\left(e_{H} e_{L}\right)^{0.5} .
$$

Dividing both sides by $\left(1-p_{L}\right)$ yields:

$$
e_{H} e_{L}+e_{L}<e_{H}^{0.5} e_{L}^{1.5}+\left(e_{H} e_{L}\right)^{0.5}
$$

or

$$
e_{L}^{0.5}\left[\left(e_{H} e_{L}\right)^{0.5}-1\right]\left(e_{H}^{0.5}-e_{L}^{0.5}\right)<0
$$


Since $e_{L}<e_{H}$, inequality (A6) holds true if and only if $e_{H} e_{L}<1$. In a similar manner, it can be verified that for $i=H$ inequality (A6) holds if and only if $e_{H} e_{L}>1$.

Case 2: $e_{H} e_{L}+\left(1-p_{L}\right)\left[e_{L}-\left(e_{H} e_{L}\right)^{0.5}\right] \leq 0$.

When the player is of type $L$, the expected rent dissipation in the contest with onesided private information, given by equation (20), is greater than that in the case of certainty, given by equation (7). To prove this, we need to show that:

$$
R D^{* * * *}=\frac{2\left(1-p_{L}\right)^{2} e_{H} n}{\left(e_{H}+1-p_{L}\right)^{2}}>\frac{2 e_{L} n}{\left(e_{L}+1\right)^{2}}=R D_{L}^{*}
$$

or

$$
\frac{e_{L} n}{\left(e_{L}+1\right)^{2}}<\frac{\left(1-p_{L}\right)^{2} e_{H} n}{\left(e_{H}+1-p_{L}\right)^{2}}
$$

This last inequality is identical to $y^{* * * *}>y_{L}^{*}$ and therefore $R D^{* * * *}>R D_{L}^{*}$.

In a similar manner, it can be verified that if the informed player is of type $H$, the expected rent dissipation in the contest with one-sided private information, given by equation (20), is smaller than that in the case of certainty.

\section{Appendix 4 - Proof of Result 3}

Case 1: $e_{H} e_{L}+\left(1-p_{L}\right)\left[e_{L}-\left(e_{H} e_{L}\right)^{0.5}\right]>0$.

For $i=L, E\left(U_{I L}^{* *}\right)<E\left(U_{I L}^{*}\right)$ holds if:

$$
n\left[\frac{e_{H} e_{L}+\left(1-p_{L}\right)\left[e_{L}-\left(e_{H} e_{L}\right)^{0.5}\right]}{e_{H} e_{L}+p_{L} e_{H}+\left(1-p_{L}\right) e_{L}}\right]^{2}<n\left(\frac{e_{L}}{e_{L}+1}\right)^{2}
$$

or

$$
\begin{aligned}
& e_{H} e_{L}^{2}+\left(1-p_{L}\right)\left[e_{L}^{2}-e_{L}\left(e_{H} e_{L}\right)^{0.5}\right]+e_{H} e_{L}+\left(1-p_{L}\right)\left[e_{L}-\left(e_{H} e_{L}\right)^{0.5}\right] \\
& <e_{H} e_{L}^{2}+p_{L} e_{H} e_{L}+\left(1-p_{L}\right) e_{L}^{2}
\end{aligned}
$$

and by rearranging we get:

$$
\left(1-p_{L}\right) e_{H} e_{L}+\left(1-p_{L}\right) e_{L}-\left(1-p_{L}\right)\left(e_{H} e_{L}\right)^{0.5}-\left(1-p_{L}\right) e_{L}\left(e_{H} e_{L}\right)^{0.5}<0 .
$$

Dividing both sides by $\left(1-p_{L}\right)$ :

$$
e_{H} e_{L}+e_{L}-\left(e_{H} e_{L}\right)^{0.5}-e_{L}\left(e_{H} e_{L}\right)^{0.5}<0
$$

or

$$
e_{L}^{0.5}\left(\left(e_{H} e_{L}\right)^{0.5}-1\right)\left(e_{H}^{0.5}-e_{L}^{0.5}\right)<0
$$


Since $e_{L}<e_{H}$, inequality (A7) holds true if and only if $e_{H} e_{L}<1$. In a similar manner, it can be verified that for $i=H \quad E\left(U_{I H}^{* * *}\right)<E\left(U_{I H}^{*}\right)$ holds if and only if $e_{H} e_{L}>1$.

Case 2: $e_{H} e_{L}+\left(1-p_{L}\right)\left[e_{L}-\left(e_{H} e_{L}\right)^{0.5}\right] \leq 0$.

For player $L$, it is clear that $E\left(U_{I L}^{* * *}\right)=0<E\left(U_{I L}^{*}\right)$ holds and for player $H$ it always holds that $E\left(U_{I H}^{* * * *}\right)=n\left(\frac{e_{H}}{e_{H}+1-p_{L}}\right)^{2}>n\left(\frac{e_{H}}{e_{H}+1}\right)^{2}=E\left(U_{I H}^{*}\right)$.

\section{Appendix 5 - Proof of Result 4}

Proof of part $1-e_{H} e_{L}<1$. We divide the proof into two cases:

Case 1: $e_{H} e_{L}+\left(1-p_{L}\right)\left[e_{L}-\left(e_{H} e_{L}\right)^{0.5}\right]>0$.

The ex-ante utility of player $I$ if player $U$ knows who he is under complete information is given by equation (23) and the ex-ante utility of player $I$ if player $U$ does not know his type is given by equation (24). Therefore, player $I$ ex-ante prefers that player $U$ does not know who he is if the following condition is fulfilled (inequality (26)):

$$
\begin{aligned}
& p_{L} n\left[\frac{e_{H} e_{L}+\left(1-p_{L}\right)\left[e_{L}-\left(e_{H} e_{L}\right)^{0.5}\right]}{e_{H} e_{L}+p_{L} e_{H}+\left(1-p_{L}\right) e_{L}}\right]^{2}+\left(1-p_{L}\right) n\left[\frac{e_{H} e_{L}+p_{L}\left[e_{H}-\left(e_{H} e_{L}\right)^{0.5}\right]}{e_{H} e_{L}+p_{L} e_{H}+\left(1-p_{L}\right) e_{L}}\right]^{2} \\
& >p_{L} n\left(\frac{e_{L}}{e_{L}+1}\right)^{2}+\left(1-p_{L}\right) n\left(\frac{e_{H}}{e_{H}+1}\right)^{2}
\end{aligned}
$$

or

$$
\begin{aligned}
& p_{L}\left\{\frac{e_{L}}{e_{L}+1}-\frac{e_{H} e_{L}+\left(1-p_{L}\right)\left[e_{L}-\left(e_{H} e_{L}\right)^{0.5}\right]}{e_{H} e_{L}+p_{L} e_{H}+\left(1-p_{L}\right) e_{L}}\right\} \\
& \left\{\frac{e_{L}}{e_{L}+1}+\frac{e_{H} e_{L}+\left(1-p_{L}\right)\left[e_{L}-\left(e_{H} e_{L}\right)^{0.5}\right]}{e_{H} e_{L}+p_{L} e_{H}+\left(1-p_{L}\right) e_{L}}\right\} \\
& +\left(1-p_{L}\right)\left\{\frac{e_{H}}{e_{H}+1}-\frac{e_{H} e_{L}+p_{L}\left[e_{H}-\left(e_{H} e_{L}\right)^{0.5}\right]}{e_{H} e_{L}+p_{L} e_{H}+\left(1-p_{L}\right) e_{L}}\right\} \\
& \left\{\frac{e_{H}}{e_{H}+1}+\frac{e_{H} e_{L}+p_{L}\left[e_{H}-\left(e_{H} e_{L}\right)^{0.5}\right]}{e_{H} e_{L}+p_{L} e_{H}+\left(1-p_{L}\right) e_{L}}\right\}<0
\end{aligned}
$$


We now simplify the first expression in brackets

$$
\begin{aligned}
\left\{\frac{e_{L}}{e_{L}+1}-\frac{e_{H} e_{L}+\left(1-p_{L}\right)\left[e_{L}-\left(e_{H} e_{L}\right)^{0.5}\right]}{e_{H} e_{L}+p_{L} e_{H}+\left(1-p_{L}\right) e_{L}}\right\}: & \\
& \frac{e_{H} e_{L}^{2}+p_{L} e_{H} e_{L}+\left(1-p_{L}\right) e_{L}^{2}-e_{H} e_{L}^{2}-\left(1-p_{L}\right)\left[e_{L}^{2}-e_{L}\left(e_{H} e_{L}\right)^{0.5}\right]}{\left(e_{L}+1\right)\left[e_{H} e_{L}+p_{L} e_{H}+\left(1-p_{L}\right) e_{L}\right]}
\end{aligned}
$$

or

$$
\begin{aligned}
& p_{L} e_{H} e_{L}+\left(1-p_{L}\right) e_{L}^{2}-\left(1-p_{L}\right)\left[e_{L}^{2}-e_{L}\left(e_{H} e_{L}\right)^{0.5}\right] \\
& \frac{-e_{H} e_{L}-\left(1-p_{L}\right)\left[e_{L}-\left(e_{H} e_{L}\right)^{0.5}\right]}{\left(e_{L}+1\right)\left[e_{H} e_{L}+p_{L} e_{H}+\left(1-p_{L}\right) e_{L}\right]}
\end{aligned}
$$

or

$$
-\frac{\left(1-p_{L}\right) e_{L}^{0.5}\left[\left(e_{H} e_{L}\right)^{0.5}-1\right]\left(e_{H}^{0.5}-e_{L}^{0.5}\right)}{\left(e_{L}+1\right)\left[e_{H} e_{L}+p_{L} e_{H}+\left(1-p_{L}\right) e_{L}\right]}
$$

In a similar manner, we can simplify the expression $\left\{\frac{e_{H}}{e_{H}+1}-\frac{e_{H} e_{L}+p_{L}\left[e_{H}-\left(e_{H} e_{L}\right)^{0.5}\right]}{e_{H} e_{L}+p_{L} e_{H}+\left(1-p_{L}\right) e_{L}}\right\}$ to obtain:

$$
\frac{p_{L} e_{H}^{0.5}\left[\left(e_{H} e_{L}\right)^{0.5}-1\right]\left(e_{H}^{0.5}-e_{L}^{0.5}\right)}{\left(e_{H}+1\right)\left[e_{H} e_{L}+p_{L} e_{H}+\left(1-p_{L}\right) e_{L}\right]}
$$

We substitute the expressions (A9) and (A10) in inequality (A8) to obtain:

$$
\begin{aligned}
& -p_{L}\left\{\frac{\left(1-p_{L}\right) e_{L}^{0.5}\left[\left(e_{H} e_{L}\right)^{0.5}-1\right]\left(e_{H}^{0.5}-e_{L}^{0.5}\right)}{\left(e_{L}+1\right)\left[e_{H} e_{L}+p_{L} e_{H}+\left(1-p_{L}\right) e_{L}\right]}\right\}\left\{\frac{e_{L}}{e_{L}+1}+\frac{e_{H} e_{L}+\left(1-p_{L}\right)\left[e_{L}-\left(e_{H} e_{L}\right)^{0.5}\right]}{e_{H} e_{L}+p_{L} e_{H}+\left(1-p_{L}\right) e_{L}}\right\} \\
& +\left(1-p_{L}\right)\left\{\frac{p_{L} e_{H}^{0.5}\left[\left(e_{H} e_{L}\right)^{0.5}-1\right]\left(e_{H}^{0.5}-e_{L}^{0.5}\right)}{\left(e_{H}+1\right)\left[e_{H} e_{L}+p_{L} e_{H}+\left(1-p_{L}\right) e_{L}\right]}\right\}\left\{\frac{e_{H}}{e_{H}+1}+\frac{e_{H} e_{L}+p_{L}\left[e_{H}-\left(e_{H} e_{L}\right)^{0.5}\right]}{e_{H} e_{L}+p_{L} e_{H}+\left(1-p_{L}\right) e_{L}}\right\}<0
\end{aligned}
$$

By taking out the common factors, we obtain:

$$
\begin{aligned}
& \frac{p_{L}\left(1-p_{L}\right)\left(e_{H}^{0.5}-e_{L}^{0.5}\right)}{\left[e_{H} e_{L}+p_{L} e_{H}+\left(1-p_{L}\right) e_{L}\right]}\left[\left(e_{H} e_{L}\right)^{0.5}-1\right] \\
& \left\langle\begin{array}{l}
\left(\frac{e_{H}{ }^{0.5}}{e_{H}+1}\right)\left\{\frac{e_{H}}{e_{H}+1}+\frac{e_{H} e_{L}+p_{L}\left[e_{H}-\left(e_{H} e_{L}\right)^{0.5}\right]}{e_{H} e_{L}+p_{L} e_{H}+\left(1-p_{L}\right) e_{L}}\right\} \\
-\left(\frac{e_{L}^{0.5}}{e_{L}+1}\right)\left\{\frac{e_{L}}{e_{L}+1}+\frac{e_{H} e_{L}+\left(1-p_{L}\right)\left[e_{L}-\left(e_{H} e_{L}\right)^{0.5}\right]}{e_{H} e_{L}+p_{L} e_{H}+\left(1-p_{L}\right) e_{L}}\right\}
\end{array}\right\}<0
\end{aligned}
$$

Since the expression $\frac{p_{L}\left(1-p_{L}\right)\left(e_{H}^{0.5}-e_{L}^{0.5}\right)}{\left[e_{H} e_{L}+p_{L} e_{H}+\left(1-p_{L}\right) e_{L}\right]}$ is positive, it can be reduced to obtain: 


$$
\left[\left(e_{H} e_{L}\right)^{0.5}-1\right]\left\{\begin{array}{l}
\left(\frac{e_{H}^{0.5}}{e_{H}+1}\right)\left\{\frac{e_{H}}{e_{H}+1}+\frac{e_{H} e_{L}+p_{L}\left[e_{H}-\left(e_{H} e_{L}\right)^{0.5}\right]}{e_{H} e_{L}+p_{L} e_{H}+\left(1-p_{L}\right) e_{L}}\right\} \\
-\left(\frac{e_{L}^{0.5}}{e_{L}+1}\right)\left\{\frac{e_{L}}{e_{L}+1}+\frac{e_{H} e_{L}+\left(1-p_{L}\right)\left[e_{L}-\left(e_{H} e_{L}\right)^{0.5}\right]}{e_{H} e_{L}+p_{L} e_{H}+\left(1-p_{L}\right) e_{L}}\right\}
\end{array}\right\}<0
$$

By simplifying the expression in the angle brackets, we obtain:

$$
\left[\left(e_{H} e_{L}\right)^{0.5}-1\right]\left\{\begin{array}{l}
\frac{e_{H}^{1.5}}{\left(e_{H}+1\right)^{2}}-\frac{e_{L}^{1.5}}{\left(e_{L}+1\right)^{2}}+\left(\frac{e_{H}^{0.5}}{e_{H}+1}\right)\left\{\frac{e_{H} e_{L}+p_{L}\left[e_{H}-\left(e_{H} e_{L}\right)^{0.5}\right]}{e_{H} e_{L}+p_{L} e_{H}+\left(1-p_{L}\right) e_{L}}\right\} \\
-\left(\frac{e_{L}^{0.5}}{e_{L}+1}\right)\left\{\frac{e_{H} e_{L}+\left(1-p_{L}\right)\left[e_{L}-\left(e_{H} e_{L}\right)^{0.5}\right]}{e_{H} e_{L}+p_{L} e_{H}+\left(1-p_{L}\right) e_{L}}\right\}
\end{array}\right\}<0
$$

After further simplification:

$$
\left[\left(e_{H} e_{L}\right)^{0.5}-1\right]\left(\begin{array}{l}
\frac{e_{L}^{1.5}}{\left(e_{L}+1\right)^{2}}\left[\frac{e_{H}^{1.5}\left(e_{L}+1\right)^{2}}{e_{L}^{1.5}\left(e_{H}+1\right)^{2}}-1\right] \\
+\frac{\left(e_{H}^{0.5}-e_{L}^{0.5}\right)\left[2 e_{H} e_{L}-\left(e_{H} e_{L}\right)^{1.5}+p_{L} e_{H}+\left(1-p_{L}\right) e_{L}\right.}{\left(e_{H}+1\right)\left(e_{L}+1\right)\left[e_{H} e_{L}+p_{L} e_{H}+\left(1-p_{L}\right) e_{L}\right]}
\end{array}\right\rangle<0
$$

We will now show that if $e_{H} e_{L}<1$, inequality (A11) is fulfilled (in other words, exante player $I$ prefers that player $U$ does not know who he is). To this end, we will show that the two expressions within the angle brackets are positive. The first expression will be positive if $\frac{e_{H}^{1.5}\left(e_{L}+1\right)^{2}}{e_{L}^{1.5}\left(e_{H}+1\right)^{2}}>1$ :

or

$$
\frac{e_{L}^{0.75}}{e_{H}^{0.75}}<\frac{e_{L}+1}{e_{H}+1}
$$

or

$$
e_{H}^{0.75} e_{L}^{0.75}\left(e_{H}^{0.25}-e_{L}^{0.25}\right)<e_{H}^{0.75}-e_{L}^{0.75}
$$

and therefore: ${ }^{15}$

$$
e_{H}{ }^{0.75} e_{L}^{0.75}\left(e_{H}{ }^{0.25}-e_{L}{ }^{0.25}\right)<\left(e_{H}{ }^{0.25}-e_{L}^{0.25}\right)\left(\left(_{H}{ }^{0.25}-e_{L}^{0.25}\right)^{2}+3 e_{H}{ }^{0.25} e_{L}{ }^{0.25}\right]
$$

We cancel the positive expression $\left(e_{H}^{0.25}-e_{L}^{0.25}\right)$ from both sides to obtain:

$$
e_{H}{ }^{0.75} e_{L}^{0.75}<\left(e_{H}{ }^{0.25}-e_{L}^{0.25}\right)^{2}+3 e_{H}{ }^{0.25} e_{L}^{0.25}
$$

or

\footnotetext{
15 In this case, the right side of the inequality was obtained by using the formula $a^{3}-b^{3}=(a-b)\left[(a-b)^{2}+3 a b\right]$, where $a=e_{H}^{0.25}$ and $b=e_{L}^{0.25}$.
} 


$$
\left(e_{H} e_{L}\right)^{0.25}\left[\left(e_{H} e_{L}\right)^{0.5}-3\right]<\left(e_{H}^{0.25}-e_{L}^{0.25}\right)^{2}
$$

Inequality (A12) is fulfilled since $e_{H} e_{L}<1$. We now consider the second expression in the angle brackets in (A11). A sufficient condition for it to be positive is $2 e_{H} e_{L}>\left(e_{H} e_{L}\right)^{1.5}$ which is equivalent to $\left(e_{H} e_{L}\right)^{0.5}<2$ or $e_{H} e_{L}<4$ where the last inequality is fulfilled since $e_{H} e_{L}<1$. Therefore, when $e_{H} e_{L}<1$ player $I$ prefers exante that player $U$ does not know who he is.

Case 2: $e_{H} e_{L}+\left(1-p_{L}\right)\left(e_{L}-\left(e_{H} e_{L}\right)^{0.5}\right] \leq 0$.

First, recall that in this case it must be that $e_{H} e_{L}<1$ and therefore it is dealt with only in the proof of part 1 of Result 4. The ex-ante utility of player $I$ if player $U$ knows who he is under complete information is given by equation (23) and the ex-ante utility of player $I$ if player $U$ does not know his type is given by equation (25). We will show that in this case (when $e_{H} e_{L}+\left(1-p_{L}\right)\left[e_{L}-\left(e_{H} e_{L}\right)^{0.5}\right] \leq 0$ ), player $I$ always prefers ex-ante that player $U$ does not know his type . In other words we must prove that inequality (27) is always fulfilled:

$$
\left(1-p_{L}\right) n\left(\frac{e_{H}}{e_{H}+1-p_{L}}\right)^{2}>p_{L} n\left(\frac{e_{L}}{e_{L}+1}\right)^{2}+\left(1-p_{L}\right) n\left(\frac{e_{H}}{e_{H}+1}\right)^{2}
$$

or

$$
\left(1-p_{L}\right)\left[\left(\frac{e_{H}}{e_{H}+1-p_{L}}\right)^{2}-\left(\frac{e_{H}}{e_{H}+1}\right)^{2}\right]>p_{L}\left(\frac{e_{L}}{e_{L}+1}\right)^{2}
$$

or

$$
\frac{\left(1-p_{L}\right)\left(2 e_{H}+2-p_{L}\right)}{\left(e_{H}+1-p_{L}\right)^{2}}>\left(\frac{e_{L}}{e_{H}}\right)^{2}\left(\frac{e_{H}+1}{e_{L}+1}\right)^{2}
$$

Prior to showing that inequality (A13) is always fulfilled, we return to the condition that must be fulfilled in the current case:

$$
e_{H} e_{L}+\left(1-p_{L}\right)\left[e_{L}-\left(e_{H} e_{L}\right)^{0.5}\right] \leq 0
$$

We will use this to prove inequality (A13). Inequality (A14), after rearranging terms, is equivalent to the following inequality:

$$
e_{L}\left(e_{H}+1-p_{L}\right) \leq\left(1-p_{L}\right)\left(e_{H} e_{L}\right)^{0.5}
$$

or 


$$
e_{H}+1-p_{L} \leq\left(1-p_{L}\right)\left(\frac{e_{H}}{e_{L}}\right)^{0.5}
$$

We square both sides to obtain:

$$
\left(e_{H}+1-p_{L}\right)^{2} \leq \frac{\left(1-p_{L}\right)^{2} e_{H}}{e_{L}}
$$

We now return to the left side of inequality (A13). Its denominator is identical to the left side of inequality (A15) and therefore we can substitute the denominator of the left side of inequality (A13) with the right side of inequality (A15) to obtain:

$$
\frac{\left(1-p_{L}\right)\left(2 e_{H}+2-p_{L}\right)}{\left(e_{H}+1-p_{L}\right)^{2}} \geq \frac{\left(1-p_{L}\right)\left(2 e_{H}+2-p_{L}\right)}{\left[\frac{\left(1-p_{L}\right)^{2} e_{H}}{e_{L}}\right]}
$$

or

$$
\frac{\left(1-p_{L}\right)\left(2 e_{H}+2-p_{L}\right)}{\left(e_{H}+1-p_{L}\right)^{2}} \geq \frac{\left(2 e_{H}+2-p_{L}\right)}{\left(1-p_{L}\right)}\left(\frac{e_{L}}{e_{H}}\right)
$$

We will now show that the right side of inequality (A13) is smaller than the expression $\frac{e_{L}}{e_{H}}$, i.e.:

$$
\frac{e_{L}}{e_{H}}>\left(\frac{e_{L}}{e_{H}}\right)^{2}\left(\frac{e_{H}+1}{e_{L}+1}\right)^{2}
$$

or

$$
\frac{e_{H}}{e_{L}}>\left(\frac{e_{H}+1}{e_{L}+1}\right)^{2}
$$

or

$$
e_{H}^{0.5}-e_{L}^{0.5}>\left(e_{H} e_{L}\right)^{0.5}\left(e_{H}^{0.5}-e_{L}^{0.5}\right)
$$

By dividing both sides by $\left(e_{H}^{0.5}-e_{L}^{0.5}\right)$, we obtain $\left(e_{H} e_{L}\right)^{0.5}<1$ or $e_{H} e_{L}<1$. Since $e_{H} e_{L}<1$ is given, then equality (A17) is fulfilled.

Based on the above and on (A16) and (A17), it can be concluded that inequality (A13) is fulfilled if the right side of inequality (A16) is larger than the left side of inequality (A17), i.e.:

$$
\frac{\left(2 e_{H}+2-p_{L}\right)}{\left(1-p_{L}\right)}\left(\frac{e_{L}}{e_{H}}\right)>\frac{e_{L}}{e_{H}}
$$

or 


$$
\frac{2 e_{H}+2-p_{L}}{1-p_{L}}>1
$$

or

$$
2 e_{H}+1>0
$$

which of course is always true.

Proof of part $2-e_{H} e_{L}=1$

From inequality (A11), it can immediately be seen that part 2 of Result 4 is true, since when $e_{H} e_{L}=1$ the left side of the inequality equals zero.

Proof of part $3-e_{H} e_{L}>1$

In order for player $I$ to ex-ante prefer that player $U$ knows who he is, inequality (A11) must hold in the opposite direction:

$$
\left[\left(e_{H} e_{L}\right)^{0.5}-1\right]\left(\begin{array}{l}
\frac{e_{L}^{1.5}}{\left(e_{L}+1\right)^{2}}\left[\frac{e_{H}^{1.5}\left(e_{L}+1\right)^{2}}{e_{L}^{1.5}\left(e_{H}+1\right)^{2}}-1\right] \\
+\frac{\left(e_{H}^{0.5}-e_{L}^{0.5}\right)\left[2 e_{H} e_{L}-\left(e_{H} e_{L}\right)^{1.5}+p_{L} e_{H}+\left(1-p_{L}\right) e_{L}\right.}{\left(e_{H}+1\right)\left(e_{L}+1\right)\left[e_{H} e_{L}+p_{L} e_{H}+\left(1-p_{L}\right) e_{L}\right]}
\end{array}\right)>0
$$

From the previous two sections, it can be concluded that the necessary condition for player $I$ to ex-ante prefer that player $U$ know who he is is $e_{H} e_{L}>1$. Given that $e_{H} e_{L}>1$, it can be seen that a sufficient condition for inequality (A18) to hold is that one of the expressions within the angle brackets be positive and one not be negative, i.e.:

$$
\frac{e_{H}^{1.5}\left(e_{L}+1\right)^{2}}{e_{L}^{1.5}\left(e_{H}+1\right)^{2}}>1
$$

and also

$$
2 e_{H} e_{L}-\left(e_{H} e_{L}\right)^{1.5}+p_{L} e_{H}+\left(1-p_{L}\right) e_{L} \geq 0
$$

The following two conditions can be derived from conditions (A19) and (A20):

\section{Possibility 1 - part 3a}

In the same way that inequality (A12) was developed above, we obtain that inequality (A19) is equivalent to:

$$
\left(e_{H} e_{L}\right)^{0.25}\left[\left(e_{H} e_{L}\right)^{0.5}-3\right]<\left(e_{H}^{0.25}-e_{L}^{0.25}\right)^{2}
$$


A sufficient condition for (A21) (which is equivalent to (A19)) to hold is that its left side be negative, i.e. when $\left(e_{H} e_{L}\right)^{0.5}<3$ or $e_{H} e_{L}<9$. A sufficient condition for (A20) to hold is $2 e_{H} e_{L} \geq\left(e_{H} e_{L}\right)^{1.5}$, which is equivalent to $2 \geq\left(e_{H} e_{L}\right)^{0.5}$ or $e_{H} e_{L} \leq 4$. Combining the two inequalities, i.e. $e_{H} e_{L}<9$ and $e_{H} e_{L} \leq 4$, we obtain that player $I$ ex-ante prefers that player $U$ knows who he is if $1<e_{H} e_{L} \leq 4$.

\section{Possibility 2 - part 3b}

It can be seen that for any given $0<p_{L}<1$ and $e_{H} e_{L}\left(e_{H} e_{L}>4\right)$, increasing $e_{H}$ (to a sufficiently high level) while at the same time reducing $e_{L}$ and leaving $e_{H} e_{L}$ unchanged will lead to the fulfillment of conditions (A20) and (A21) (the latter is equivalent to (A19)). This means that when the difference between $e_{L}$ and $e_{H}$ is sufficiently large the conditions will be fulfilled.

\section{Appendix 6 - proof of Result 5 (part 2)}

We will show that if player $I$ of type $H$ knows that player $U$ will know his type if he doesn't declare it in the first stage, then he will decide to declare that he is of type $L$ even though he is of type $H$.

From (5) the expected payoff of player $H$ in a complete information contest equals $E\left(U_{I H}\right)=\frac{e_{H} x_{H}}{e_{H} x_{H}+y} n-x_{H}$. The optimal reaction of player $H$ for any $y$ played by player $U$ equals:

$$
x_{H}=\frac{\left(e_{H} y n\right)^{0.5}-y}{e_{H}}
$$

If player $I$ of type $H$ declares that he is of type $L$ and player $U$ reacts according to his reaction function, then from equation (6) we obtain:

$$
y_{L}=\frac{e_{L} n}{\left(e_{L}+1\right)^{2}}
$$

and according to (A22), the best response of player $I$ of type $H$ is:

$$
x_{H}^{L}=\frac{\left(e_{H} y_{L} n\right)^{0.5}-y_{L}}{e_{H}}=n\left[\frac{\left(e_{L} e_{H}\right)^{0.5}}{e_{H}\left(e_{L}+1\right)}-\frac{e_{L}}{e_{H}\left(e_{L}+1\right)^{2}}\right]
$$

where the lower index of $x_{H}^{L}$ describes the type of player, $H$, and the upper index describes his declaration in the first stage, $L$. This last expression is always positive. 
Substituting (A24) into the expected payoff of player $I$ of type $H$ (equation (5)), we obtain:

$$
E\left(U_{I H}^{L^{*}}\right)=n\left[\frac{\left(e_{L}+1\right) e_{H}^{0.5}-e_{L}^{0.5}}{\left(e_{L}+1\right) e_{H}^{0.5}}\right]^{2}
$$

where the upper index of $E\left(U_{I H}^{L^{*}}\right)$ indicates that player $H$ declares that his type is $L$ in the first stage. If on the other hand, player $I$ of type $H$ had not declared his type and as a result player $U$ had revealed that he is of type $H$, the expected payoff of player $I$ of type $H$ is given by equation (9): $E\left(U_{I H}^{*}\right)=n\left(\frac{e_{H}}{e_{H}+1}\right)^{2}$. Player $I$ of type $H$ would decide not to reveal his real type and would declare that he is of type $L$ even though he is of type $H$ if $E\left(U_{I H}^{L^{*}}\right)>E\left(U_{I H}^{*}\right)$ :

$$
n\left[\frac{\left(e_{L}+1\right) e_{H}^{0.5}-e_{L}^{0.5}}{\left(e_{L}+1\right) e_{H}^{0.5}}\right]^{2}>n\left(\frac{e_{H}}{e_{H}+1}\right)^{2}
$$

Thus, (A26) holds if:

$$
\left[1-\left(e_{H} e_{L}\right)^{0.5}\right)\left(e_{H}^{0.5}-e_{L}^{0.5}\right)>0
$$

Since $e_{H} e_{L}<1$ and $e_{L}<e_{H}$, (A27) must hold, which means that it worthwhile for player $H$ to declare that he is player $L$ in the first stage.

\section{Appendix 7 - Proof of Result 6}

Solving the first-order conditions, $\frac{\partial E\left(U_{I i}\right)}{\partial x_{i}}=0 \quad \forall i=1,2, \ldots, N$ and $\frac{\partial E\left(U_{U}\right)}{\partial y}=0$, we obtain:

$$
y^{* * *}=n\left(\prod_{j=1}^{N} e_{j}\right)\left\{\frac{\sum_{j=1}^{N}\left[p_{j}\left(\prod_{k=1, k \neq j}^{N} e_{k}\right)^{0.5}\right]}{\prod_{j=1}^{N} e_{j}+\sum_{j=1}^{N}\left[p_{j} \cdot\left(\prod_{k=1, k \neq j}^{N} e_{k}\right)\right]}\right\}^{2}
$$

and 


$$
x_{i}^{* * *}=\frac{n\left\{p_{i}\left(\prod_{k=1, k \neq i}^{N} e_{k}\right)+\sum_{j=1, j \neq i}^{N}\left[p_{j}\left(e_{i} e_{j}\right)^{0.5}\left(\prod_{k=1, k \neq(j, i)}^{N} e_{k}\right)\right]\right\}\left\{\prod_{j=1}^{N} e_{j}+\sum_{j=1, j \neq i}^{N}\left\langle p_{j}\left\{\left(\prod_{k=1, k \neq(j, i)}^{N} e_{k}\right) \cdot\left[e_{i}-\left(e_{j} e_{i}\right)^{0.5}\right]\right\}\right\}\right\}}{\left\{\prod_{j=1}^{N} e_{j}+\sum_{j=1}^{N}\left[p_{j} \cdot\left(\prod_{k=1, k \neq j}^{N} e_{k}\right)\right]\right\}^{2}}
$$

The expected net payoff of the informed player becomes:

(A28)

$$
E\left(U_{I i}^{* *}\right)=n\left\{\frac{\prod_{j=1}^{N} e_{j}+\sum_{j=1, j \neq i}^{N}\left\langle p_{j}\left\{\left(\prod_{k=1, k \neq(j, i)}^{N} e_{k}\right) \cdot\left[e_{i}-\left(e_{j} e_{i}\right)^{0.5}\right]\right\}\right.}{\prod_{j=1}^{N} e_{j}+\sum_{j=1}^{N}\left[p_{j} \cdot\left(\prod_{k=1, k \neq j}^{N} e_{k}\right)\right]}\right\}^{2} .
$$

Consider the case in which uncertainty is disadvantageous to player $I$. For this to be so, it must be (for player $I$ of type $i$ ) that $E\left(U_{I i}^{* *}\right)<E\left(U_{I i}^{*}\right) \forall i=1,2, \ldots, N$. Using (A28), this last inequality can be written as:

$$
\sum_{j=1, j \neq i}^{N}\left\{p_{j}\left(\prod_{k=1, k \neq(j, i)}^{N} e_{k}\right) \cdot\left[e_{i}^{0.5}-e_{j}^{0.5}\left[1-\left(e_{j} e_{i}\right)^{0.5}\right]\right\}<0 .\right.
$$

It can be seen that Result 6 is derived directly from this last inequality. 